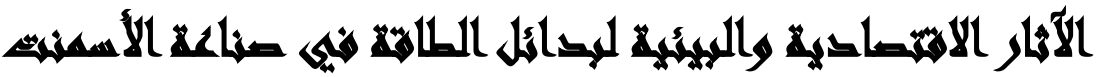

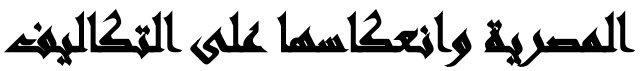

\section{[Ir]}

أحمد نبيل سيد محمد(')- عمرو حسين عبد البر(')- عيد رشاد عبد القادر(')

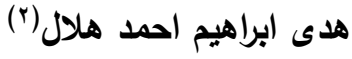

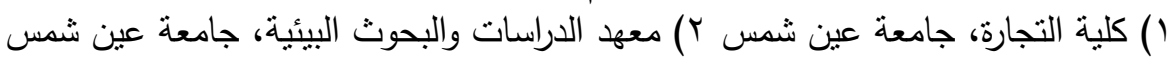

\section{المستخلئ}

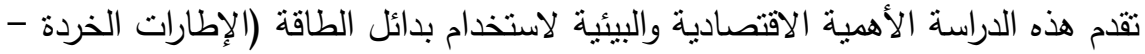
المخلفات الصُلبة) في توفير الطاقة النقليدية (الفحم-المازوت-الغانة الطانية الطبيعي) اللازمة لإنتاج

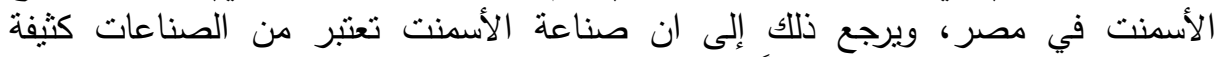

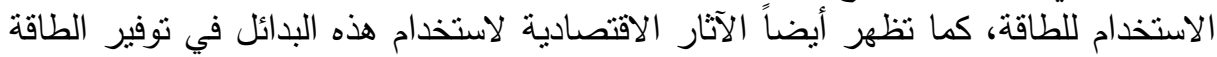

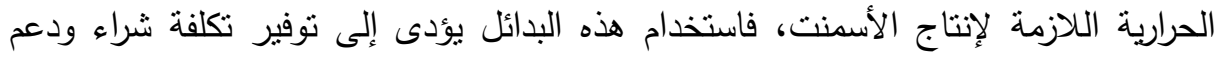

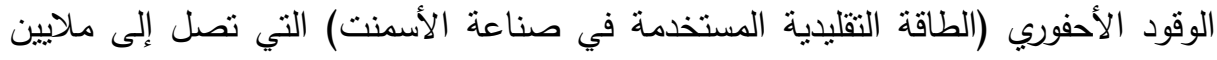

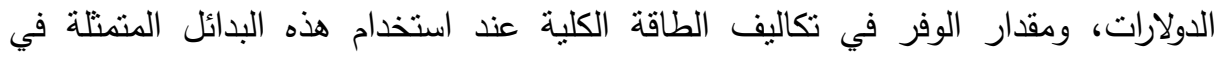

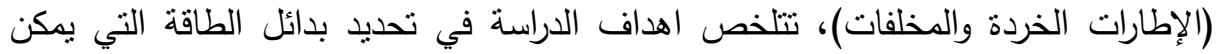

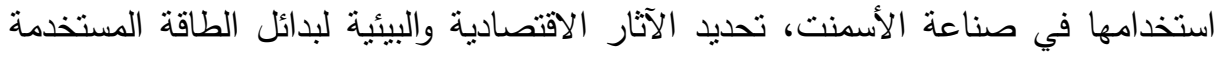

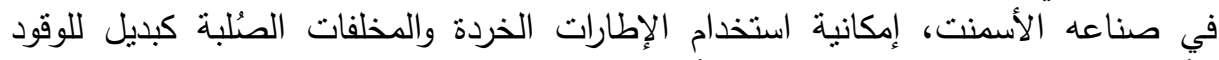

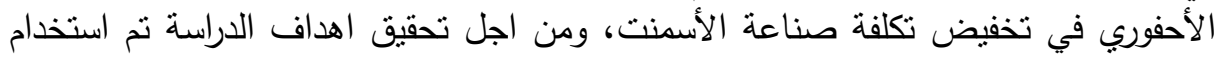

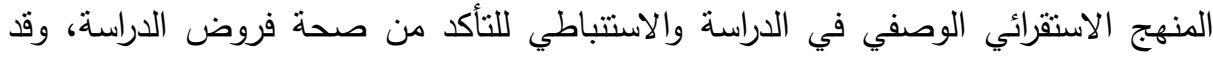

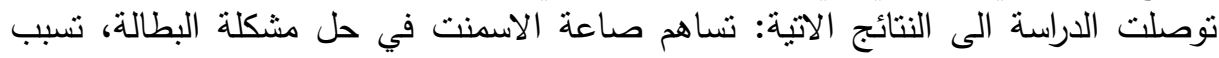

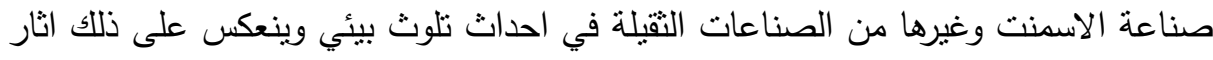

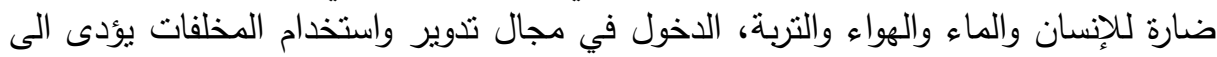

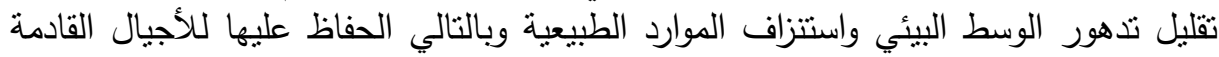

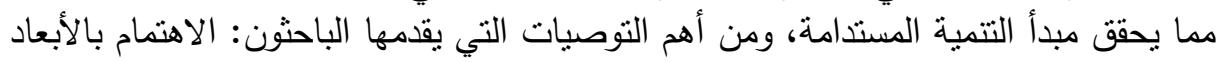

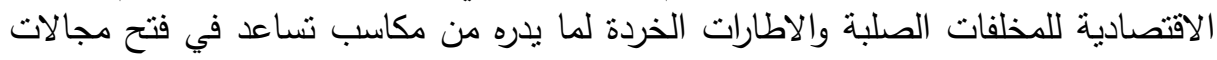

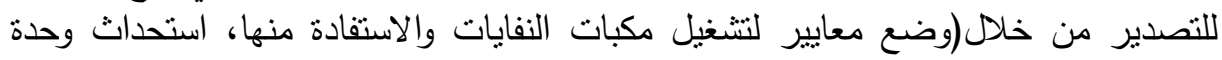

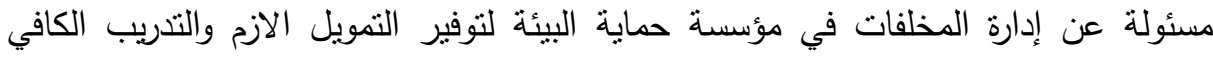

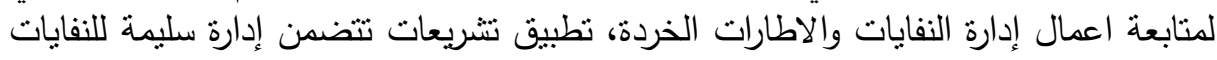

$$
\text { المجلد السادس والأربعون، الجزء الثالث، بونيو } 9 \text { ب ب ا }
$$




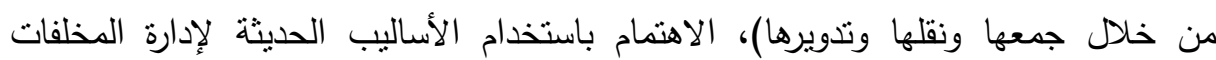

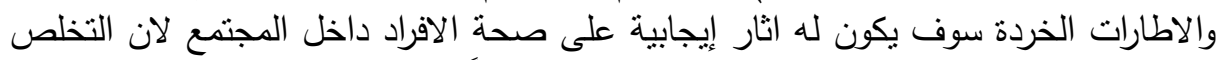

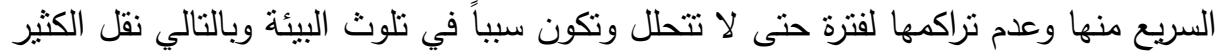

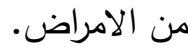
كلمات مفتاحية: ( صناعة الأسمنت- الإطارات الخردة - تحويل النفايات إلى طاقة - الآثار البيئية لصناعة الأسمنت (كلتاعة )

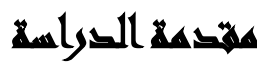

تعتبر صناعة الأسمنت ومواد البناء من الصناعات الجديرة بالعناية والرعاية فهي من

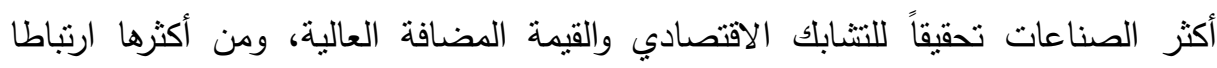

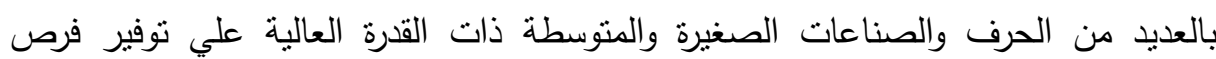

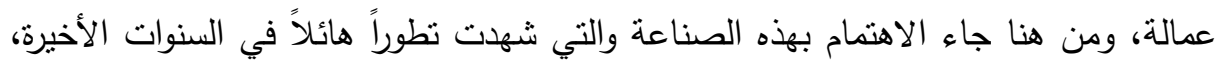

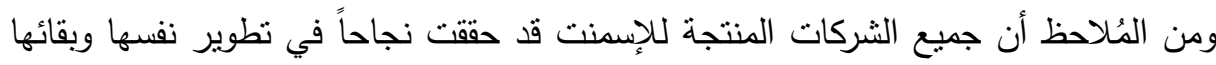
على الساحات الدولية، مما يعكس النضج في صناعة النّاعة الأسمنت في مصر والذي يتيح فكرً جيدً لكيفية الدخول في المرحلة القادمة، وخلق ميزة تتافسية للأسمنت المصري في الجودة لئه

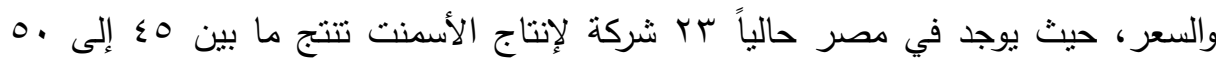

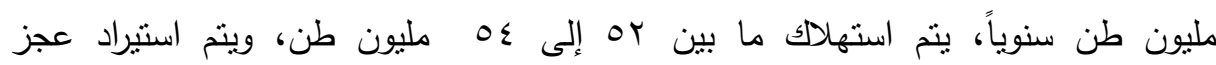

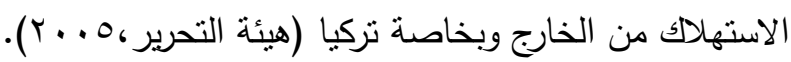
يستخدم الأسمنت في طائفة واسعة من التطبيقات ولا يقتصر على على عمليات البناء

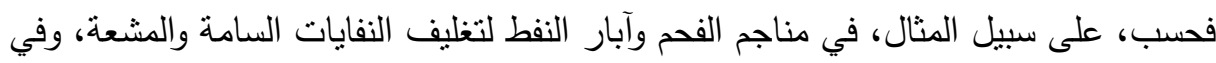
التطبيقات الطبية متل الأسنان والعظام، بالإضافة إلى عمليات تغليف النفايات النووية على الثى الرغم من أن الأسمنت يستخدم في الغالب لإنتاج الخرسانة التي ينت استخدامها في تنثييد المباني، والجسور والسدود وغيرها من الهياكل، التي تدعو في بعض الألي الأحيان لاستخدام

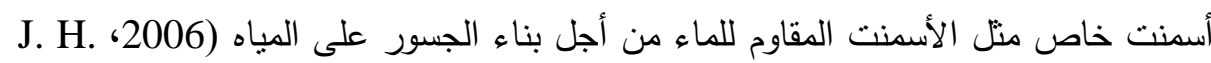

لذلك فإن صناعة البناء والتشييد من الصناعات الرائدة في تدهور البيئة من خلال

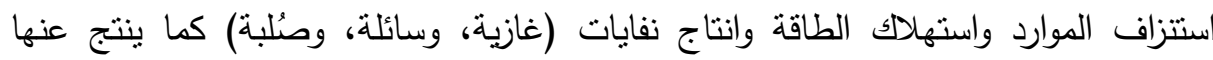


كميات كبيرة من انبعاثات الغازات المسببة للاحتباس الحرارى، وتتنمي صناعة الأسمنت إلى

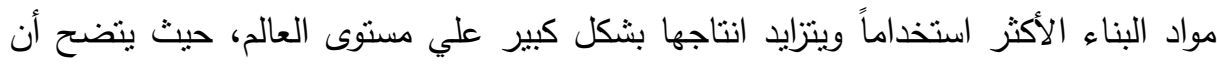

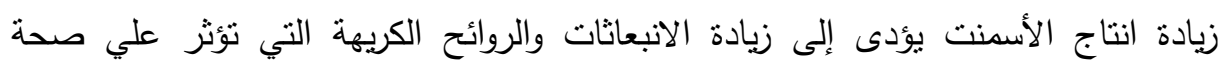
الإنسان، بالإضافة إلى أن الانبعاثات الناتجة من مصانع الأسمنت نسبب زئن قلقاً كبيراً، وتحتاج إلى تعامل خاص معها مثل غبار ثاني أكسيد الكربون(COX) وثاني أكسيد الكبريت(Stajanča M\&others،2012)(SO

تم تحليل استهلاك مصادر توليد الطاقة المتتوعة بجمهورية مصر العربية، وقد اتضح أن

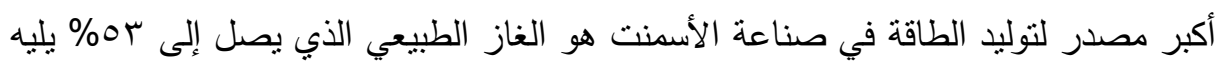

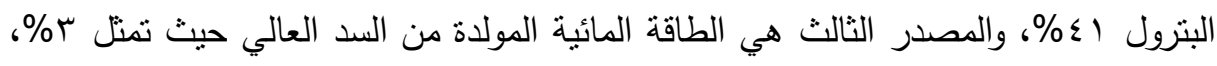

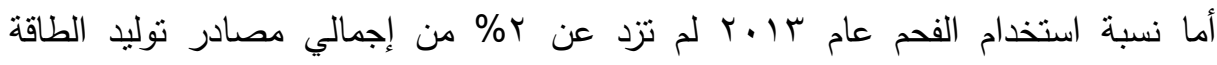

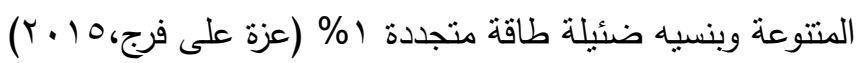
وتعرض هذه الدراسة الأهمية الاقتصادية من استخدام الإطارات الخردة والمخلفات كوقود لتوليد الطاقة الحرارية اللازمة لتجهيز الأسمنت لتوفير الاحتباجات منه بتكاليف منخفضة الإهنة ومناسبة لتدعيم صناعة التشييد والبناء وذلك لدخول جمهورية مصر العربية في مرحلة

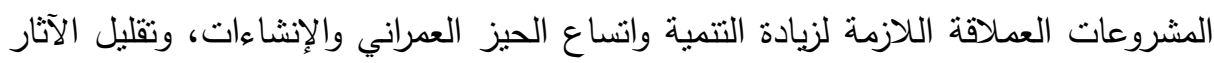
البيئية التي تتتج من حرق تلك المخلفات للتخلص منها من خلال استخدامها كوقود للطاقة في صناعة الأسمنت، وتقليل الاعتماد على الوقود التقليدي المتمنل في الوقود الأحفوري غير المتجدد وارتفاع تكلفته التي تؤدي بدورها إلى ارتفاع أسعار الأسمنت.

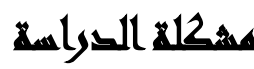

ومن خلال اطلاع الباحثن على الدراسات السابقة التي نم عرضها بشكل تفصيلي في

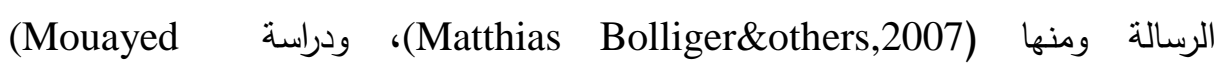
Makhlouf,2014)، ودراسة ( B.O. Oboiriena B.C. Northa,2016)، ودراسة (M.L. ‘Boukour,2016) ودراسة (Bang Shu,2016) (Baoshan Huang

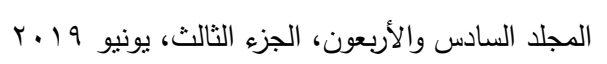


Benmalek

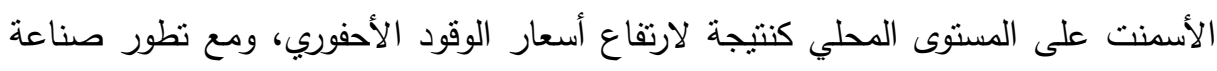

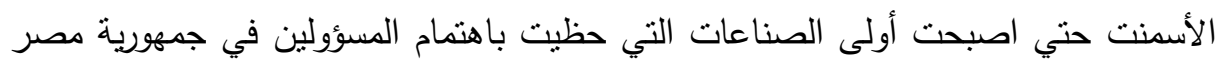

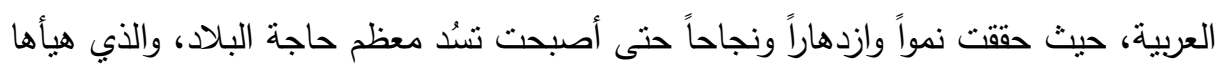
لدخول مرحلة المنافسة العالمية في التصدير، وقد كان لهذه الصناعة آثاراً بيئيةً جانبيةً خطيرةً وتعتبر مسئولة عن ·ء \% من أسباب التلوث البيئي بسبب اعتمادها على الفحم كوقود رئيسي في صناعة الاسمنت لأنه يعتبر من المصادر الأساسية للحصول علي طابة طاقة، ويتكون فحم

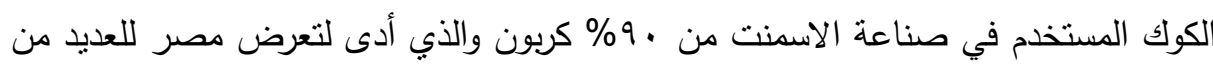

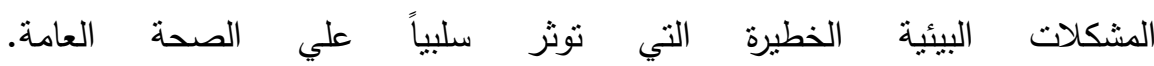
.(AliHasanbeigi\&others, 2014)

\section{أسئلا القرواسلة}

يمكن عرض مشكلة الدراسة من خلال الإجابة على السؤال الرئيسي التالي والذي يمنل جوهر المشكلة وهو: " ماهي الآثار الاقتصادية والبيئية لبدائل الطاقة في صناعة الإنس الأسمنت

$$
\text { وانعكاسها على التكاليف "وهن: }
$$

ويُستمد من هذا السؤال عدة أسئلة، منها:

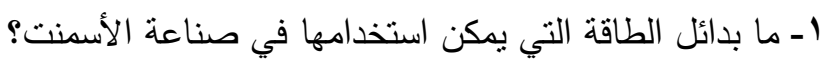

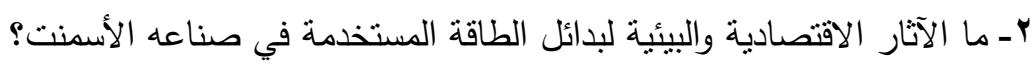

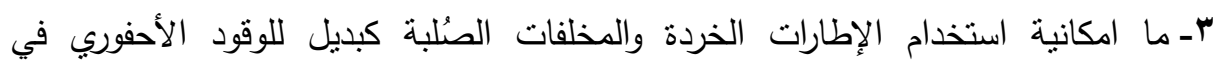
تخفيض تكلفة صناعة الأسمنت؟

\section{أهساهيت السراسة}

من خلال ما نم عرضه من مشكله الدراسة يمكن تحديد الهدف الرئيسي من الدراسة،

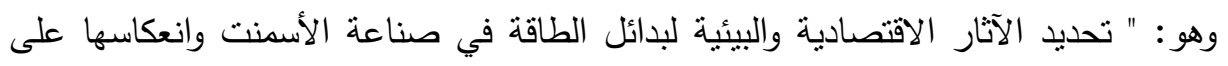




\section{ويتحقى هذا الههف من خلال مجموعه من الأهداف الفرعية التالية:}

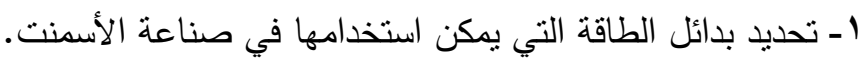

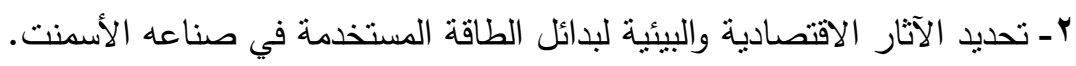

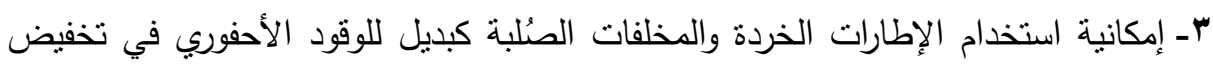
تكلفة صناعة الأسمنت.

\section{أهمي التواسمة}

تكمن أهمية هذه الدراسة في ندرة الدراسات باللغة العربية في هذا الموضوع وأيضاً في

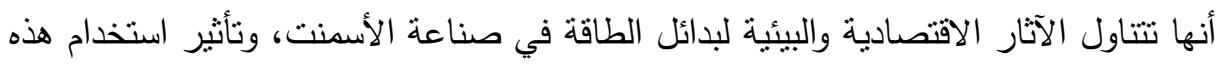

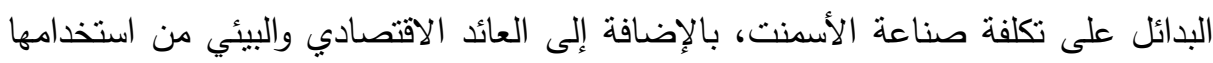
من خلال الأهمية العملية والعلمية. الأهمية العملية: تحديد الآثار البيئية الناتجة من صناعة الأسمنت، وارتفاع تكاليف الطاقة التقليدية المستخدمة في تلك الصناعة التي تؤدي إلى زيادة أسعار الأسمنت، وبالتالي حدوث فجوة بين الإنتاج والاستهلاك مما يتطلب نوفير وايجاد بدائل للطاقة أقل في تكلفةً وأقل ضرراً

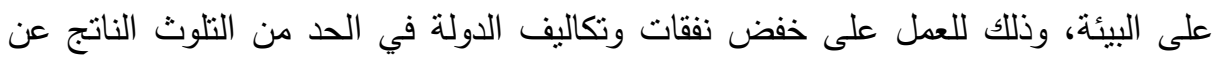
هذه الصناعة، ونرجو أن تساهم هذه الدراسة في رصيد المعرفة الموجود وتحقيق الغرض منها. الأهمية العلمية: نساعد هذه الدراسة في تقديم التوصيات لمصانع الأسمنت وذللك لمعرفة الطريقة التي تناعد في خفض تكاليف صناعة الأسمنت من خلال استخدام بدائل الطاقة بدلاًا من استخدام الوقود الأحفوري غير المتجدد، مما يحقق منفعة اقتصادية وبيئية عند استخدام

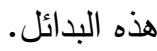

\section{هروغ التوراسة}

تم صياغة الفروض التالية كأسباب محتملة للمشكلة محل الدراسة كالتالي: الفرض الأول: توجد فروق ذات دلالة احصائية عند استخدام بدائل الطاقة في صناعة الأسمنت المصرية تتعكس على التكاليف. 
الفرض الثاني: توجد فروق ذات دلالة إحصائية بين تكلفة الطاقة المستخدمة من الإطارات

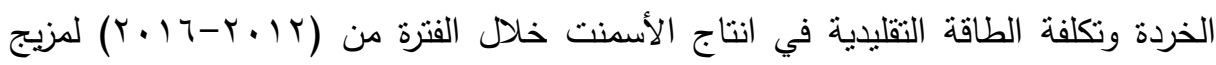
الطاقة المصري الفرض الثالث: توجد فروق ذات دلالة إحصائية بين تكلفة الطاقة المستخدمة من الإطارات

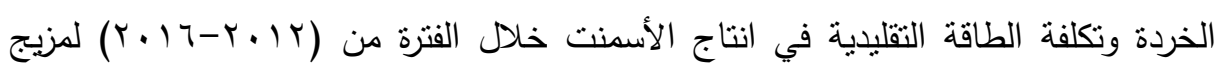
الطاقة الأوروبي الفرض الرابع: توجد فروق ذات دلالة إحصائية بين تكلفة الطاقة المستخدمة من المخلفات

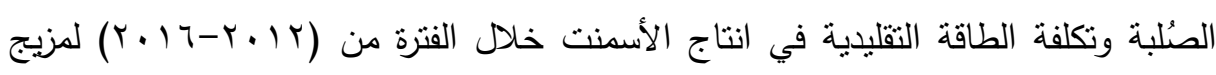
الطاقة المصري الفرض الخامس: نوجد فروق ذات دلالة إحصائية بين تكلفة الطاقة المستخدمة من المخلفات

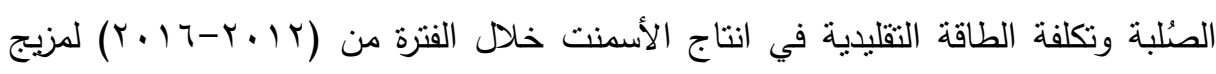
الطاقة الأوروبي.

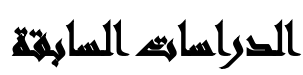

( ) تعرضت دراسة،Moses P.M. Chinyama.2012 ) إلى خصائص الوقود البديل الذى يمكن استخدامه في صناعة الأسمنت، وتهدف هذه الدراسة إلى عرض بدائل الوقود

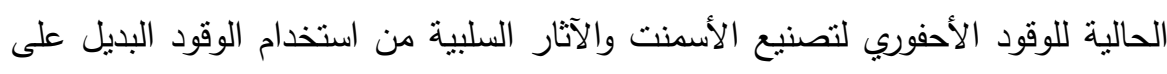

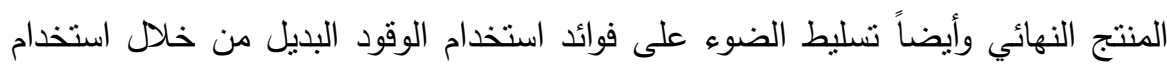

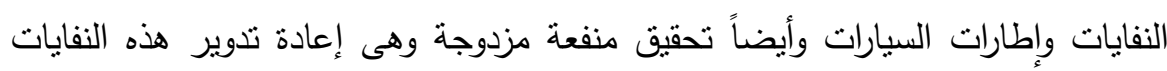

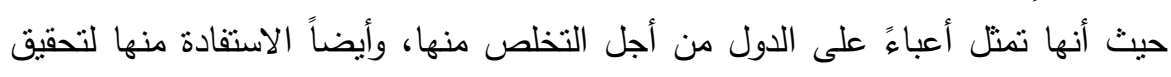
منافع اقتصادية لتقليل تكاليف انتاج الأسمنت أنياء r) تعرضت دراسة (Baoshan Huang،Xiang Shu 2014) : إلى إعادة تدوير

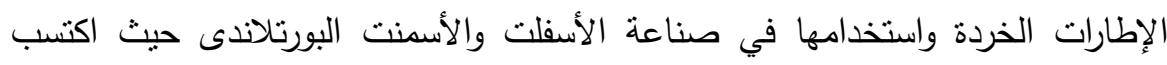

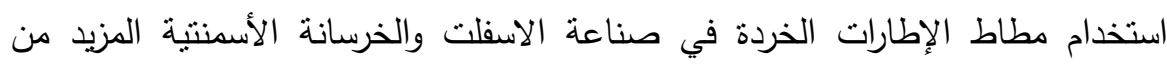
الاهتمام بسبب الفوائد الاقتصادية والبيئية المرنبطة بإعادة تدويره، وقد ثبت نجاح إعادة 
تدوير الإطارات الخردة في الحصول على المطاط اللازم في رصف الاسفلت وبخاصة في تكنولوجيا الاسفلت المطاطي من خلال مقاومته وقدرته على تحمل درجات الحرارة العالية

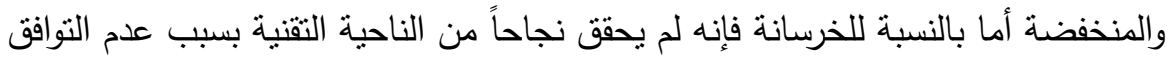
بين التركيبات الكيميائية، وقد تم اقتراح طرقاً عدة للقضاء على خصائصه السلبية، وإلى ندانى اللحظة يتم بذل الكثير من الجهد لتحسين ونجاح هذه العملية واستخدامها في الهندسة ولنهاء

الإنشائية.

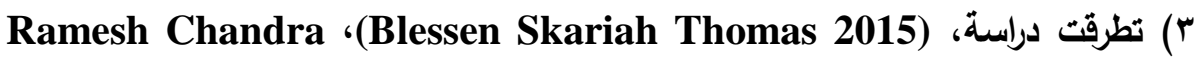
Gupta المدى الطويل، وهدفت الدراسة إلى أنه يمكن استخدام المطاط الموجود في الإطارات الخردة في صناعة الأسمنت بنسبة •r\% في المناطق التي تكون فيها قوة الضغط كبيرة،

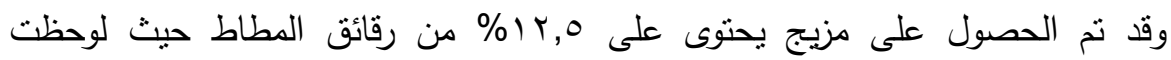
مقاومته في امتصاص الماء وتفاعله مع الكربون والأكاسبد، وبالتالي يمكن التلخيص بأن هن بأن هناك مستقبلاً واعداً في استخدام مطاط الإطارات الخردة كبديل جزئي في صناعة ونها الأسمنت، وأن هناك كثيراً من التجارب للوصول إلى الخئل الخليط الأفضل.

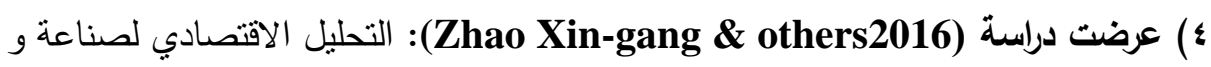
تحويل النفايات إلى طاقة في الصين، مع تزايد نوليد النفايات الصُلبة في الصين نتيجة

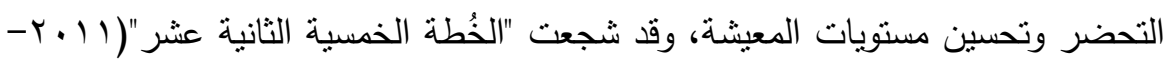

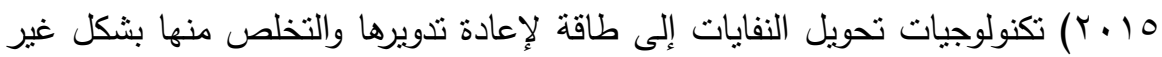
ضار للبيئة، وتلعب محطة تحويل النفايات إلى طاقة دوراً هاماً للوصول إلى إلى أهداف

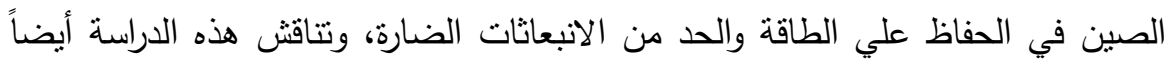

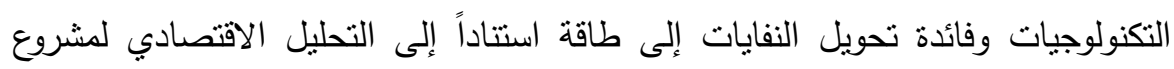
تحويل النفايات إلى طاقة (العائد على الاستثمار، القيمة الحالية الصافية، معدل العائد 
ه) قدمت دراسة (Nickolaos Chatziaras \& others 2016): استخدام الوقود المشتق

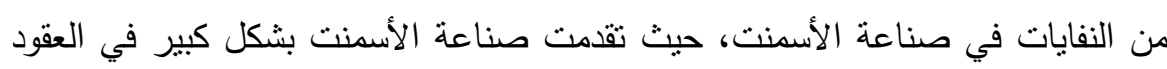
القليلة الماضية حيث شمل تقام الوقود التقليدي المستخدم في الأفران الثقليدية علي (الفحم

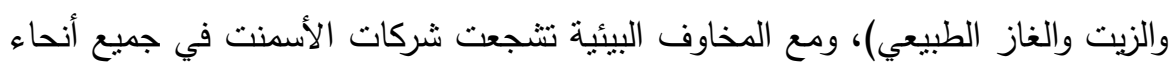

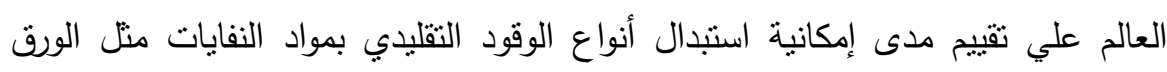

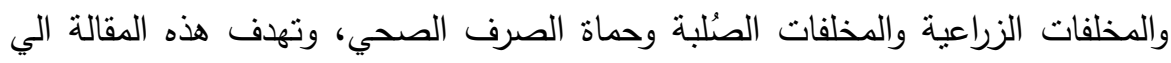

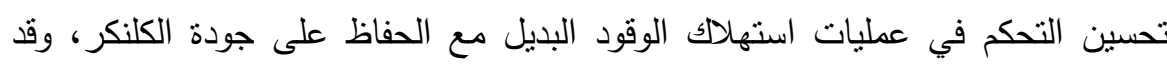
أظهرت الدراسة أيضاً كيفية استبدال الوقود النقليدي بالوقود البديل، وكان لذانلكان أهمية كبيرة

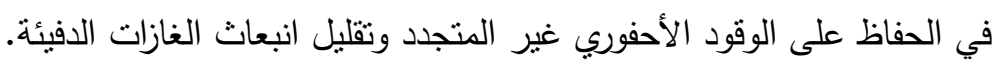

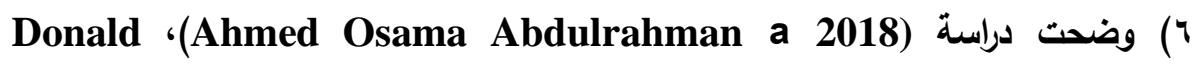
Tuisingh b

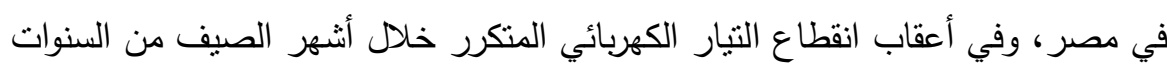

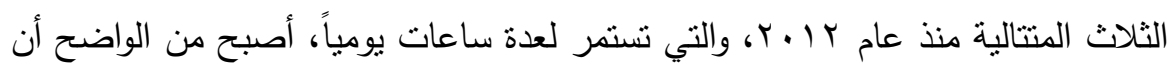

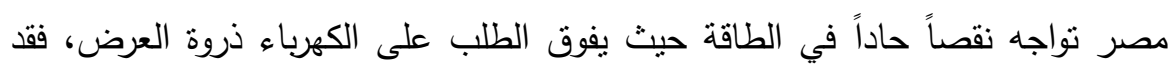

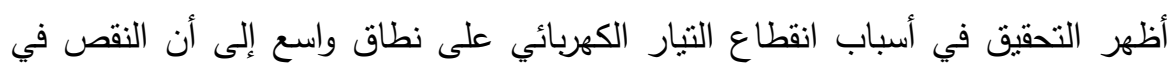

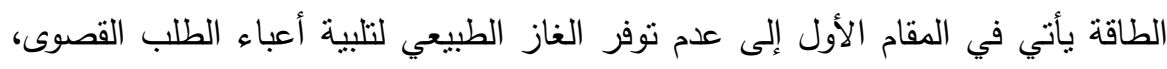

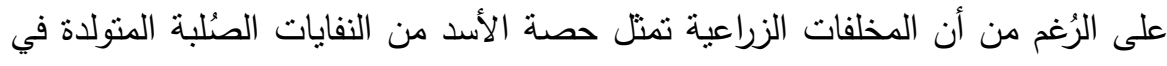

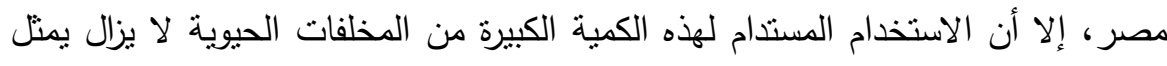

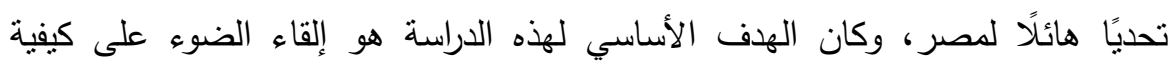

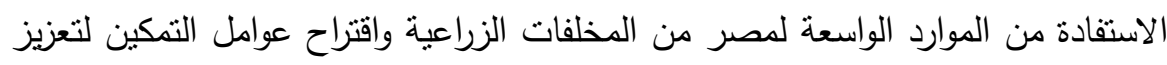

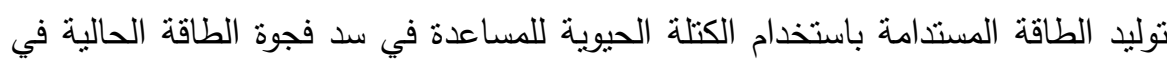

$$
\text { مصر باستخدام الموارد المحلية. }
$$

ومن المُلاحظ أن معظم الدراسات السابقة لم تتطرق للتأثير البيئي لصناعة الأسمنت باستخدام الوقود الأحفوري(التقليدي) أو إلى كيفية استخدام الوقود البديل المتمثل في (الإطارات

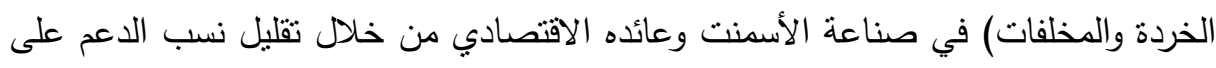


الوقود التقليدي الذي يستهلك ملايين الدولارات لشرائه، بالإضافة إلى نأثر الجانب البيئي نتيجة

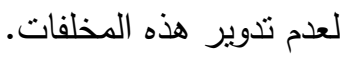

\section{الإسار اللنظيه}

1- الأسمنت: عبارة عن مسحوق جاف ناعم، لديه القدرة على التصلب عند إضافة الماء، مما بمنحه خصائص تماسكيه وتلاصقيه، تمنحه القدرة على ربط مكونات الخرسانة مع بعضها البعض، وهو مادة ناتجة عن طحن وتتعيم ناتج حرق المادة الجيرية المحتوية أساساً على كربونات الكالسيوم والمادة الطينية المحتوية على أكاسيد السيليكون والألومنيوم وخالية بصفة خاصة من الأكاسيد الملونة منل أكسيد الحديديك، ويتم خلط هذه المواد الطياد خلطاً جيداً بنسب معينة حسب خواص المواد قبل عملية الحرق، وتضاف لناتج المواد المحروقة (الكلنكر) مادة الجبس (كبريتات الكالسيوم المائية أو مشتقاتها) ويُستخدم الأسمنت بشكل عام في الصناعات الإنشائية، لربط المواد الصناعية أو الطبيعية، بشكلٍ

يمنحها القوة لمقاومة التأثيرات البيئية المختلفة (موقع المنظمة العربية للتنمية والتصنيع). يجب عدم الخلط بين الخرسانة والأسمنت، فالأسمنت يشير إلى المسحوق الجاف المستخدم في ربط المواد الكلية للخرسانة، وللإسمنت المستخدم في البناء نوعان هما الأسمنت المائي والأسمنت غير المائي، وتعتبر صناعة الأسمنت من الصناعات الاستراتيجية وهي مع فئي ذللك صناعة بسيطة مقارنة بالصناعات الكبرى، وتعتمد على توفير المواد الخام اللازمة لذللك. r - الكلنكر: هو مادة رابطة يلزم لكي تتكون ما لا يقل عن ثلثي الوزن من سليكات ثنائي وثلاني الكالسيوم، بينما يحتوي المتنقي من الوزن على أكاسيد الألومنيوم والحديد (موقع لون المنظمة العربية للتتمية والتصنيع). r- الطاقة: هي إحدى الخصائص الموجودة حولنا في الكون ولا يوجد تعريف محدد للطاقة، لأن الطاقة حتى الآن تتعدى حدود فهم الإنسان، وأقرب ما يمكننا أن نعرف الطاقة

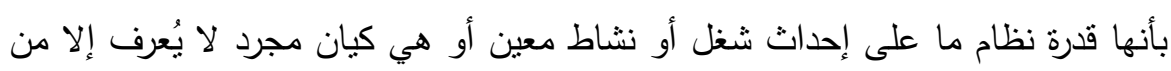

خلال تحولاته (James L، Oschman‘2015) 
ويمكن تقسيم الطاقة الي نوعين رئيسين هما (الطاقة الأولية والطاقة الثانوية) ويتم استخراج الطاقة الأولية من البيئة بينما يتم استخراج الطاقة الثانوية من الطاقة الأولية مثل

الكهرباء والوقود ( Yasar، Demirel،2012) ع - الطاقة الحرارية: تعتبر من الصور الأساسية للطاقة التي يمكن أن تتحول كل صور الطاقة إليها، فهي طاقة تتشاً من حركة الذرات ويمكن اعتبارها الطاقة المتعلقة بالحرارة فعند تشغيل الآلات المختلفة باستخدام الوقود، تكون الخطوة الأولى هي حرق الونة الوقود

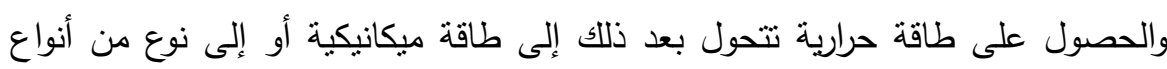
الطاقة. ويوجد أنواع أخرى للطاقة مثل (الطاقة الثمسية، الطاقة النووية، الطاقة الكيميائية،

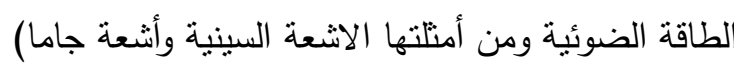
ه- الوقود الأحفوري: يحتوي الوقود الأحفوري على نسبة عالية من الكربون ويشمل الفحم والغاز والنفط، وهو مركبات عضوية تتتج من عمليات البناء الضوئي، حيث أن المواد العضوية من نبات أو حيوان والتي لم تتحلل بشكل كامل في باطن الأرض لملايين السنين وبفعل عوامل الضغط والحرارة، نتج هذا الوقود والذي يحتوي على طاقة كيميائية نشأت لئن

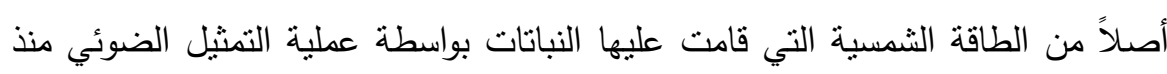
ملايين السنين.

צ- الإطارات الخردة: تعتبر من أنواع النفايات المرهقة في التخلص منها، ويتم انتاج ما

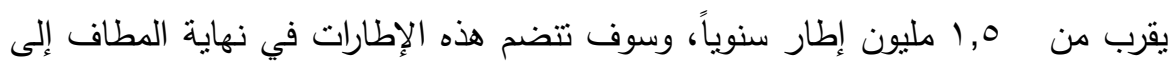
تيار النفايات، ووفقاً للوائح الإتحاد الأوروبي التي تحظر التخلص من من الإطارات الخردة

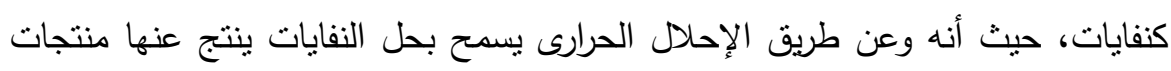
ثانوية مفيدة، ويجب التعامل مع الإطارات الخردة كنفايات نموذجية يمكن إعادة تدويرها

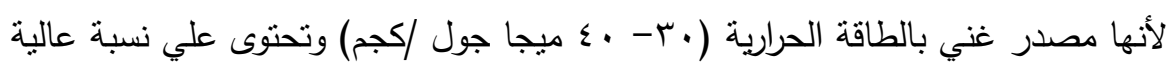

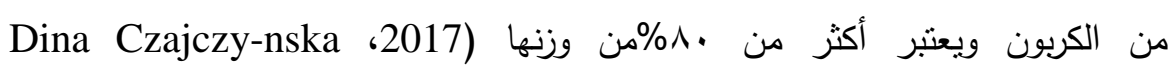
.(a\&others 
- V المخلفات الصُّبة: يشهد العالم زيادة مطردة في عدد السكان أدت إلى كثافة الأنشطة الاقتصادية وما ينتج عنها من مخلفات تمثل خطورة على البيئة، وتعتبر إدارة المخلفات وخاصة الصناعية مشكلة بيئية حقيقية في معظم أنحاء العالم، حيث بدأت بنأ نأخذ اهنماماً أكثر فأكثر من قبل الحكومات، وقد أصدرت العديد من البلدان قوانين وتتشريعات للإدارة والسيطرة السليمة على للمواد الضارة والمخلفات، حيث حددت القوانين والخطوط الرئيسية لإدارة المخلفات، غير أن التوجيهات لتتفيذ تلك القوانين والتشريعات في كثير من البلاد

$$
\text { مازالت غير مفعلة بشكل كامل(هدى منصور القرماني، (1 + ب) . }
$$

1 - مفهوم البيئة: نجد أن مفهوم البيئة قد بدأ بلفت الأنظار ويسترعي الانتباه بما يتضمنه من تحديات ومخاطر على جميع الأصعدة الدولية والإقليمية والمحلية، اعتباراً من مؤتمر لئه

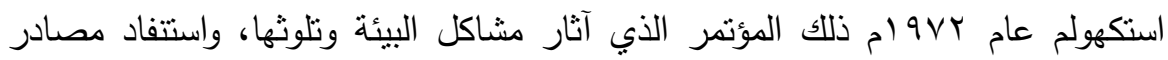

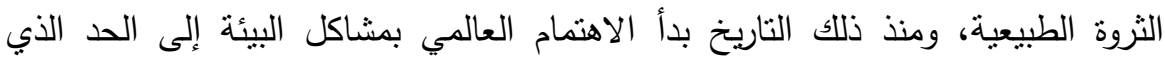

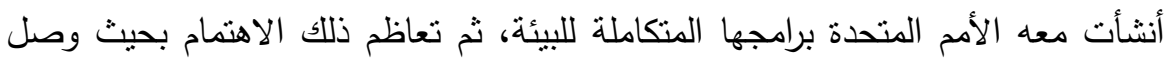
إلى أقصى درجاته مع عقد مؤتمر قمة الأرض الذي عقد في ريو دي جانيرة الأنيرو بالبرازيل عام

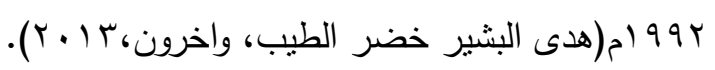

تعريف البيئة: هي الإطار الذي يعيش فيه الإنسان ويحصل منه على مقومات حياته من

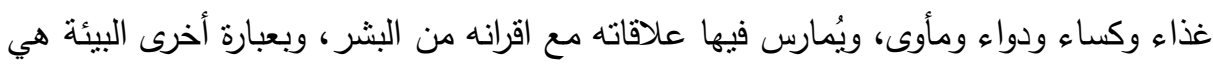
مجموعة من العناصر الطبيعية والصناعية التي تمارس فيها الحياة الإنسانية، وهي أيضاً المحيط الذي يعيش فيه الفرد ويؤثر فيه ويتأثز به.

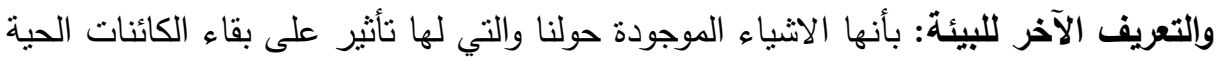

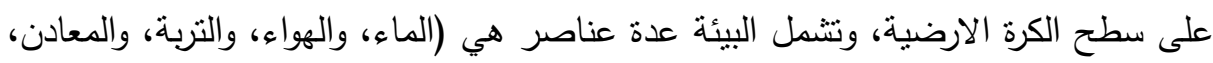

$$
\text { والمُناخ، والكائنات الحية). }
$$

9- التلوث البيئي: عُرف التلوث البيئي بأنه كل تغير كمي أو كيفي في مكونات البيئة الحية وغير الحية، والذي لا تقدر الأنظمة البيئية على استيعابه دون أن يختل توازنها،

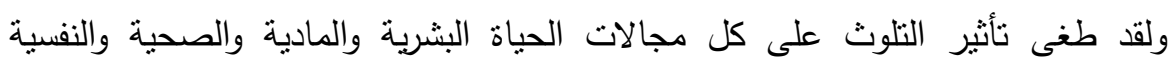

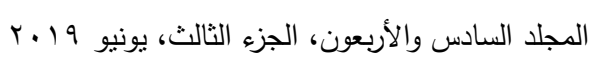


والاجتماعية والاقتصادية، كما يعنى التلوث أيضاً قيام الإنسان بطريقة مباشرة أو غير

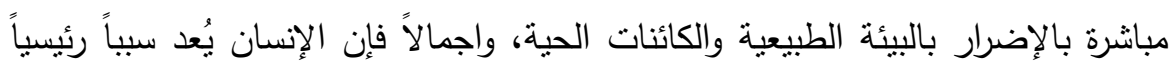

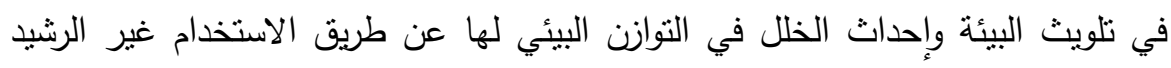
وغير الأمنل لمكونات النظام البيئي(هدى البشير خضر الطيب، واخرون، با ـ ب).

\section{هنهبية الصراسة}

أولاً: أسلوب الدراسة: تستمد هذه الدراسة أهميتها من الموضوع ومدى ضرورته في ظل

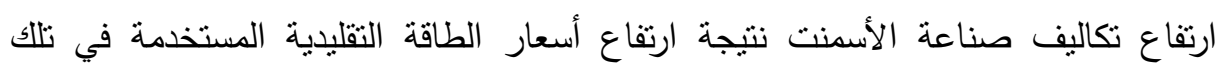

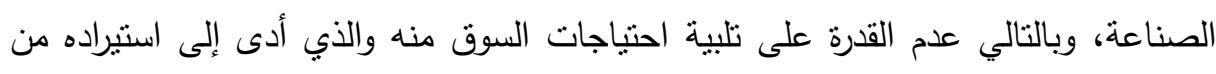

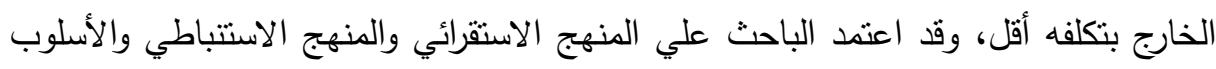
التحليلي (الكمي) وذلك من خلال:

المنهج الاستقرائي: والذي يعتمد على الدراسات المكتبية في استقراء بعض الكتب والدوريات

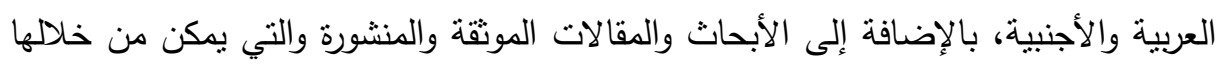

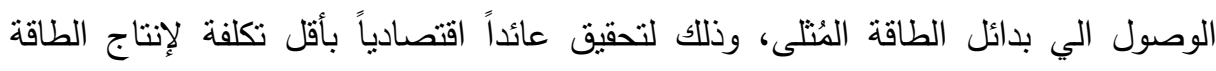

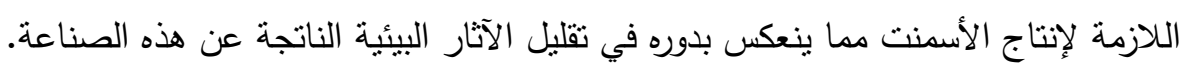

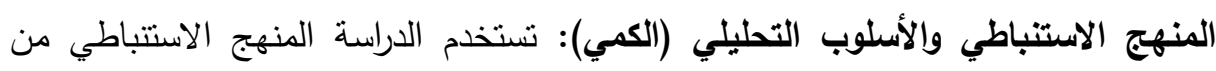
خلال ربط النظريات الاقتصادية بالواقع واثنات مدي انطباقها بالواقع، وسوف يقوم الباحث ببناء إطار متكامل لأبعاد مشكلة الدراسة وأهدافها في إطار علمي من خلا بل تحليل البيانات

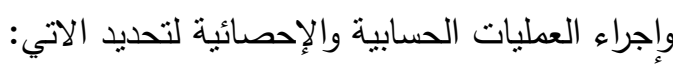
ا ا. تحديد كمية الإنتاج السنوي لصناعة الأسمنت والطاقة اللازمة للإنتاج. r. حساب الطاقة الحرارية المنولدة من الإطارات الخردة والمخلفات (بدائل الطاقة). r. تحديد كمية الإطارات الخردة التي ينم تكهينها سنويا وكمية المخلفات المتولدة سنوياً.

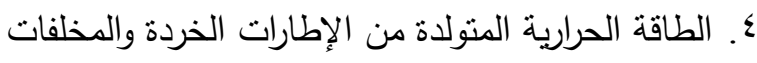

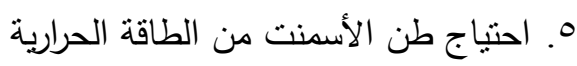
T. القدرة الإنتاجية للإطارات الخردة والمخلفات كوقود بديل في صناعة الأسمنت الطن 


\section{مصوض القراسما}

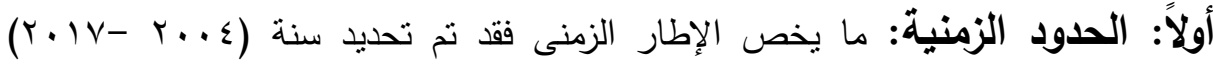

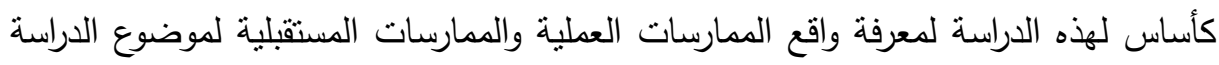

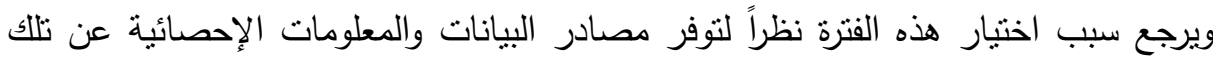

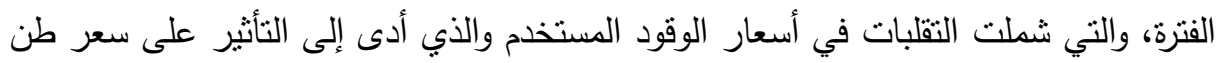

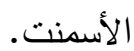

ثثانياً: الحدود المكانية: سيتم تطبيق هذه الدراسة في قطاع صناعة الأسمنت بجمهورية

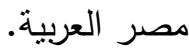

\section{خطلا الترواسلة}

يستعرض الباحثون طبيعة الطاقة في صناعة الأسمنت ومصادر الطاقة النقلبدية

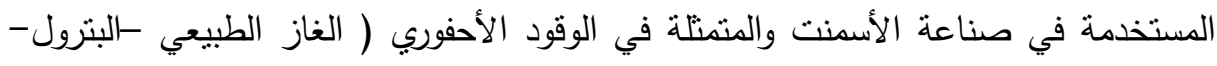

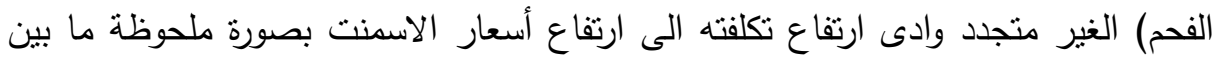

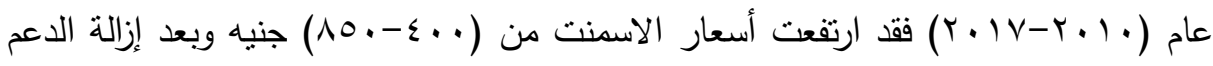
عن هذا الوقود الأحفوري فسوف يؤدى ذلك الى ارتفاع أسعار الاسمنت لان نسان نسبة استخدام

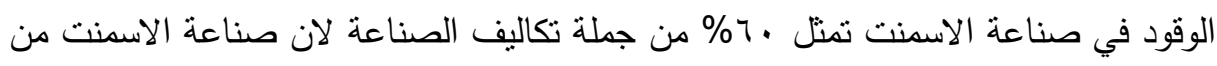

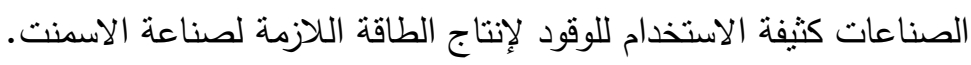

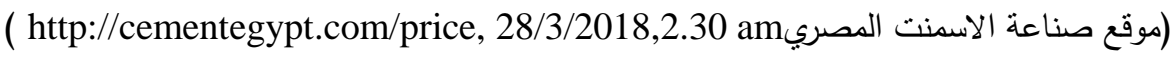
وتم النطرق وعرض نظرة عامة عن أنواع الوقود البديل الذى يمكن استخدامه في

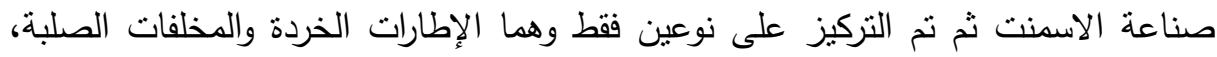

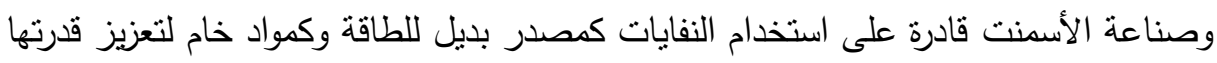

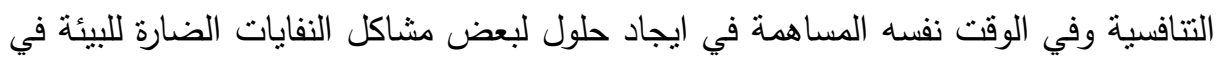

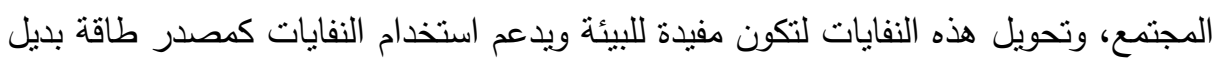
في صناعة الأسنت بالمبادئ العامة لإدارة النفايات المأخوذة من الآتحاد الأوروبي لإنيات

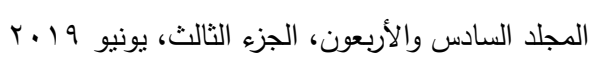


والمستويات الوطنية والنفايات المستعملة كوقود بديل في قمائن الأسمنت، سوف تكون قد دمرت في محارق مخصصة وتحل محل الوقود الأحفوري ويزيد من انتعاش الطاقة.

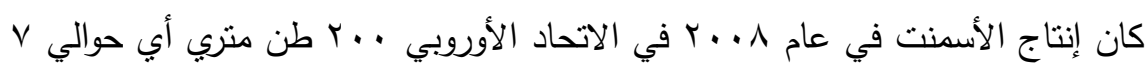

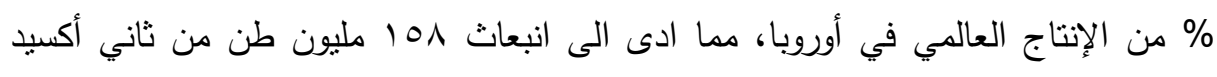

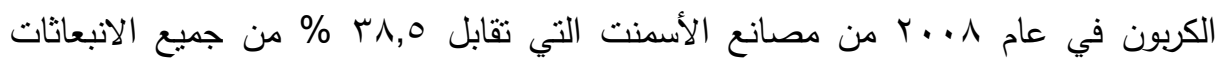

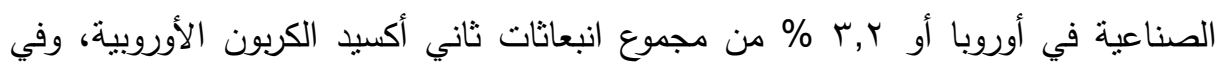

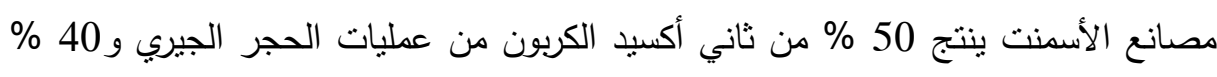

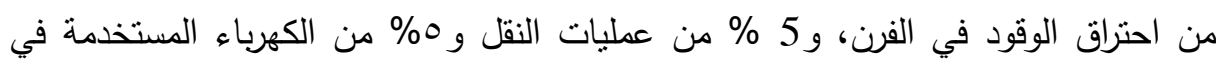

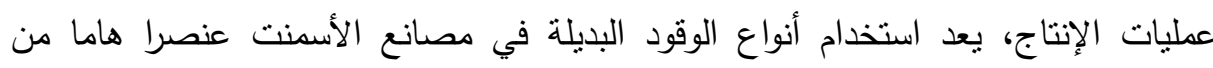

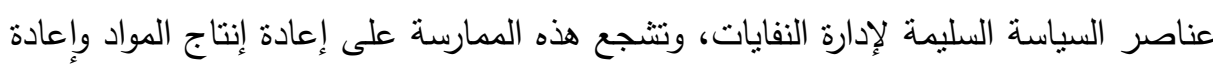

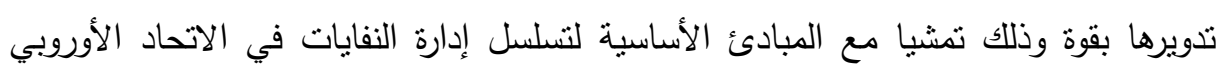

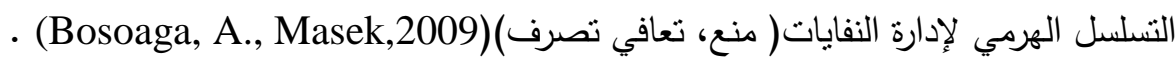

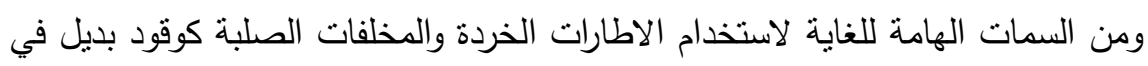

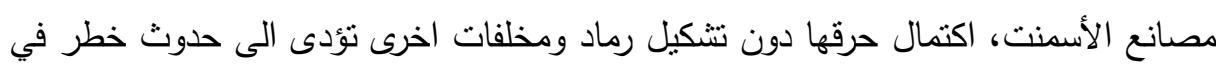
الغلاف الجوي، حيث ان المعادن المنطلقة من الاطارات اثثاء الاحتراق في قمائن الأسمنت

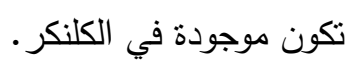

وتم اجراء بعد العمليات الحسابية والاحصائية لتحديد كمية الإنتاج السنوي لصناعة الأسمنت والطاقة اللازمة للإنتاج، وحساب الطاقة الحرارية المتولدة من الإطارات الخردة والمخلفات (بدائل الطاقة)، تحديد كمية الإطارات الخردة التي يتم تكهينها سنويا وكمية التهنة

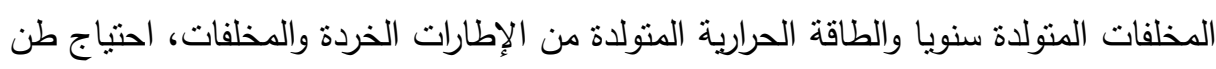
الأسمنت من الطاقة الحرارية، القدرة الإنتاجية للإطارات الخردة والمخلفات كوقود بديل في الإرات الحردة صناعة الأسمنت. الطاقة الحرارية وتكلفة انتاج الاسمنت باستخدام الوقود التقليدي: يستهلك انتاج الاسمنت نحو (7-0,0) مليون وحدة حرارية علي حسب العملية الانتاجية ويتراوح سعر المليون وحدة

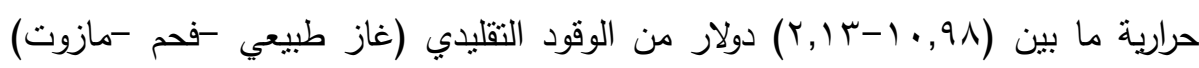


ويوضح الجدول (1) احتباج طن الاسمنت من الطاقة الحرارية وأجمالي تكلفة الطاقة الحرارية

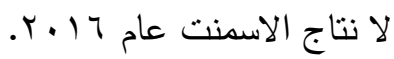
جدول(1): احتياج طن الاسمنت من الطاقة الحرارية وأجمالي تكلفة الطاقة الحرارية لأنتاج

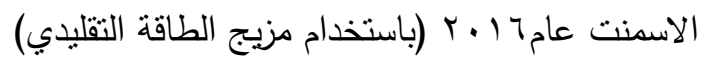

\begin{tabular}{|c|c|c|c|c|}
\hline 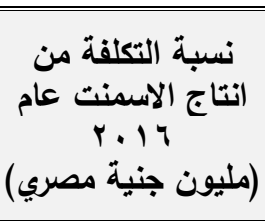 & طن الاسمنة التكلة من & الحرارية لمليونة الطاقة & من منبة الاستخدام الطاقة & نوع الوقود \\
\hline V00.,Tा & IVI & $0 \xi, Y \wedge q$ & $\%$ \% . & الغاز الطبيعى \\
\hline$T r V I \varepsilon, Y r Y$ & 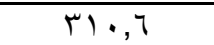 & $1 \leqslant \vee, q 1$ & $\%$ \%. & المازوت \\
\hline YIYTE,07T & $\{\lambda 1,7$ & $r \cdot r, 199$ & $\% 1 \ldots$ & الإجمالى \\
\hline
\end{tabular}

المصدر: بواسطة الباحث

يبين الجدول (1) ان تكلفة الطاقة الحرارية لمليون وحدة حرارية عند استخدام الغاز

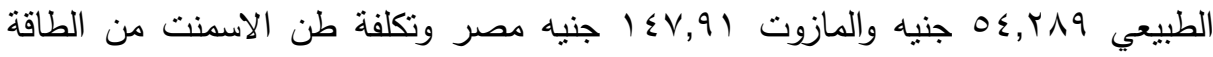

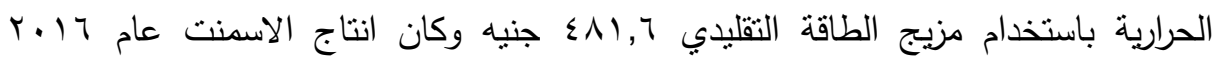

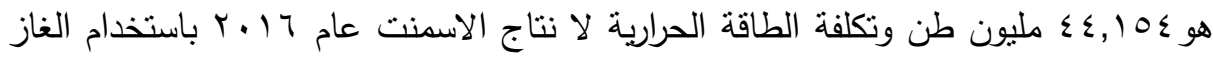

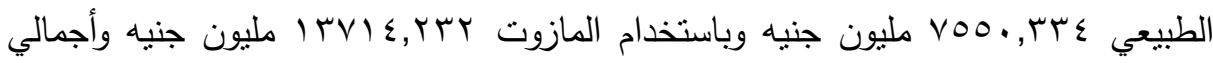

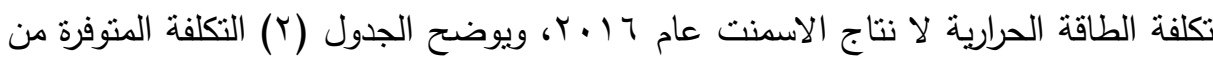

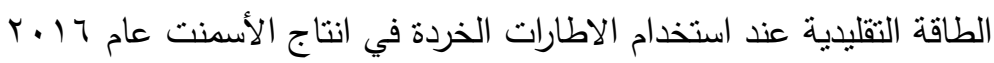
الجدول(ץ): التكلفة المنوفرة من الطاقة التقليدية عند استخدام الاطارات الخردة في انتاج

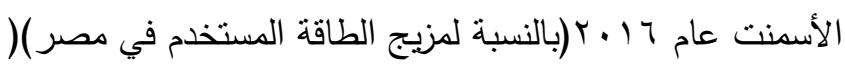

الوحدة: مليون جنيه

\begin{tabular}{|c|c|}
\hline التكلفة المتوفرة & نوع الوقود \\
\hline$r \leqslant \|, 1$ & الغاز الطبيعي \\
\hline$\varepsilon r \vee q, 0$ & المازوت \\
\hline $70 Y r, 7$ & الإجمالي \\
\hline
\end{tabular}

المصدر: بواسطة الباحث 


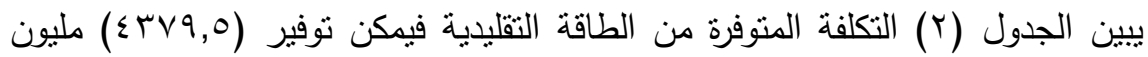
جنية من المازوت وتوفير (1,1) مليون جنيه من الغاز الطبيعي عند استخدام الاطارات الخردة كوقود في صناعة الأسمنت.

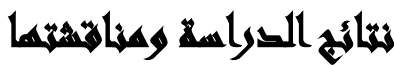

أولاً: نتائج الدراسة التطبيقية: يستعرض الباحث فيما يلي أهم النتائج التي توصل اليها

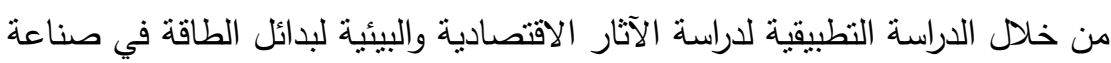
الأسمنت المصرية وانعكاسها على التكاليف ، ويمكن تقسيم هذه النتائج الى البنود الآتية : بعد دراستتا التفصيلية لمصادر الوقود المختلفة لصناعة الاسمنت (التقليدية والبديلة التي يمكن استخدامها) تمكنا من التوصل إلى النتائج الآتية:

1- يمكن تحقيق منفعة اقتصادية من استخدام الوقود البديل متمثلة في توفير نكلفة شراء الوقود التقليدي (الأحفوري) وتوفير هذه التكلفة وانفاقها في قطاعات أخرى مثل (قطاع التعليم والصحة).

r- يعد استخدام أنواع الوقود البديلة في مصانع الأسمنت عنصرا هاما من عناصر السياسة

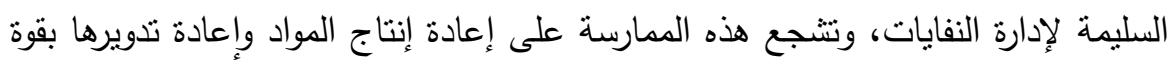

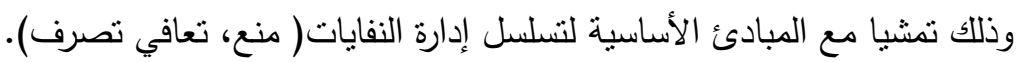

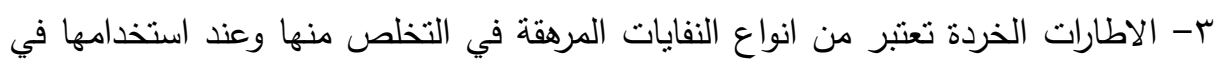
صناعة الاسمنت يتم تحقيق استفادة (افتصادية وبيئية) معاً.

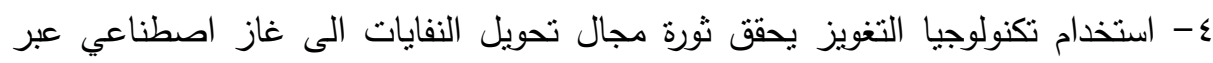
تغويز انواع كثيرة من النفايات، مثل: النفايات الصلبة، والوقود المشتق من النفايات والبلاستيك الذي لا يعاد تدويره، والمخلفات الصناعية والزراعية، وحماة الصرف الصحي

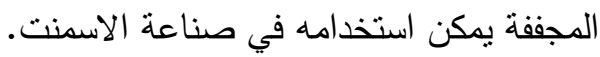


ثانياً: النتائج الخاصة باختبارات الفروض:

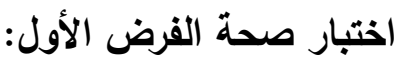

1- ينص الفرض الأول على: " توجد فروق ذات دلالة احصائية عند استخدام بدائل الطاقة في صناعة الأسنت الدصرية تنعكس على التكاليف." وفقاً لتحليل تكاليف بدائل الطاقة

ونتائج هذا التحليل وفقاً للجدول (r) جدول(ץ): الفرق في تكلفة الطاقة الحرارية لإنتاج الأسمنت

\begin{tabular}{|c|c|c|c|c|c|c|c|c|}
\hline \multirow[b]{2}{*}{ مستوى الدلالة } & \multirow[b]{2}{*}{ قيمة } & \multicolumn{2}{|c|}{ انتاج الأسمنت } & \multicolumn{2}{|c|}{ المخلفات الصُلبة } & \multicolumn{2}{|c|}{ الإطارات الخردة } & \multirow[b]{2}{*}{ السنة } \\
\hline & & التقليدية & $\begin{array}{c}\text { الإطارات } \\
+ \\
+ \\
\text { المخلفات }\end{array}$ & الأسمنت & الطرارية & الأسمنت إنتاج & الحرارية الطاقة & \\
\hline \multirow{7}{*}{$\bullet, \cdots$} & \multirow{7}{*}{$7, \leqslant 1$} & $\{9, \vee \backslash$. & $00, .11$ & $\varepsilon \varepsilon,+11$ & YTI, & $11, \cdot 1$. & $O V, \Lambda I$ & $r .1 r$ \\
\hline & & $\varepsilon \varepsilon, Y \wedge 1$ & וחוז,000 & $\varepsilon \varepsilon, 11$ & YT, T & 11, & $09, \leq 0$ & $r \cdot 1 r$ \\
\hline & & $\varepsilon \vee, \vee q$. & $07, .11$ & $\varepsilon \varepsilon,+11$ & YTI, & $1, \ldots$ & Tr, YT & $r .1 \leq$ \\
\hline & & $\leq r, \vee q \leq$ & $07, \cdot 11$ & $\varepsilon \varepsilon,+11$ & TrI, & $I r, \cdot V \cdot$ & אז,זד & $r .10$ \\
\hline & & $\varepsilon \varepsilon, 10 \varepsilon$ & $0 \wedge, 111$ & $\varepsilon \varepsilon,+11$ & YTI, T & $1 \varepsilon, 1 \ldots$ & $V \varepsilon, 1 Y$ & $r .17$ \\
\hline & & $\leq 0, V \leq 7$ & $07,1.9$ & $\leq \varepsilon,+11$ & rו, & $1,1, \ldots$ & $71,09 \leq$ & المتوسط \\
\hline & & $r, \wedge \wedge 0$ & $I, r \cdot V$ & $\cdot$, & $\cdot$, & $1, r \cdot \varepsilon$ & $7, \pi \circ 7$ & الانحراف \\
\hline
\end{tabular}

المصدر: اعداد الباحث في ضوء تحليل بيانات الدراسة

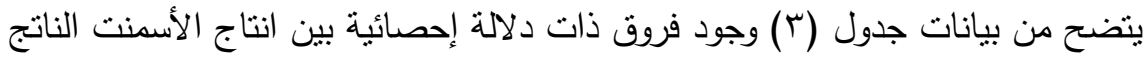

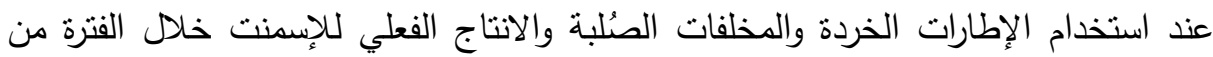

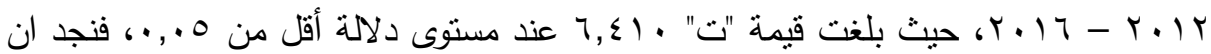

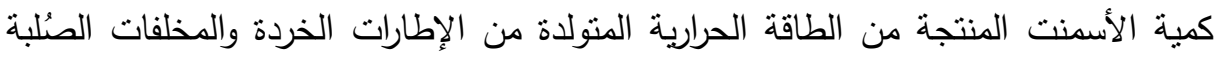

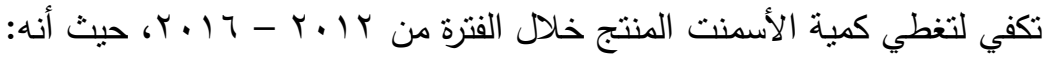

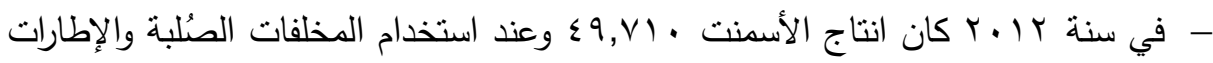

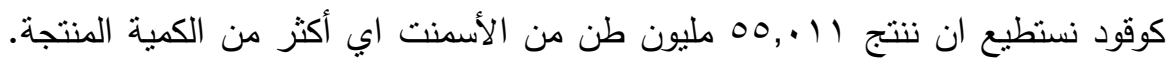

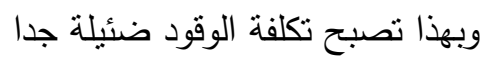




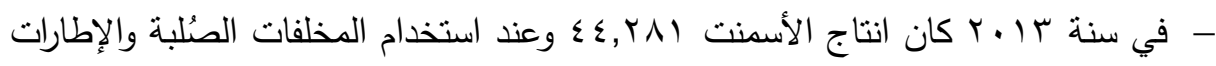
كوقود نستطيع ان ننتج اسب, اسر مليون طن من الأسمنت اي أكثر من الكمية المنتجة.

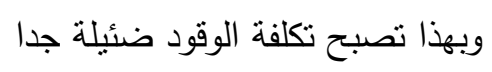

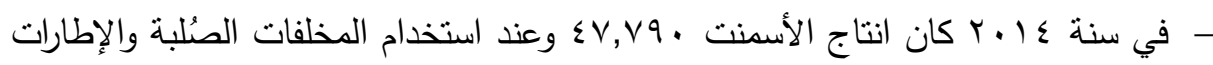
كوقود نستطيع ان نتتج 11 .,.4ه مليون طن من الأسمنت اي أكثر من الكمية المنتجة

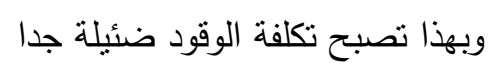

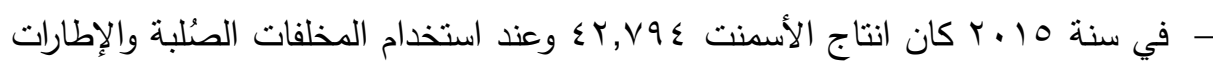

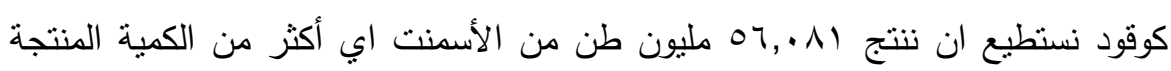

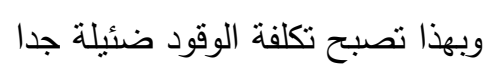

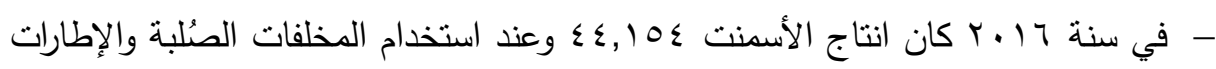
كوقود نسنطيع ان ننتج القرار: قبول صحة فرض الدراسة القائل "يوجد أثز اقتصادي وبيئي ذات دلالة الإنئة إحصائية لبدائل الطاقة في صناعة الأسمنت المصرية وينعكس ذلك على خفض الته التكاليف"، ومن ثن يلاحظ ان الاثر الاقتصادي تمنل في تقليل التكلفة، وتمثل الاثر البيئي في استخدام الإطارات

والمخلفات الصُلبة حيث منع ذلك تكدس المخلفات مما قد تسبب اضرار بيئية ضخمة.

$$
\text { اختبار صحة الفرض الثاني: }
$$

r- ينص الفرض الثاني على: " توجد فروق ذات دلالة إحصائية بين تكلقة الطاقة

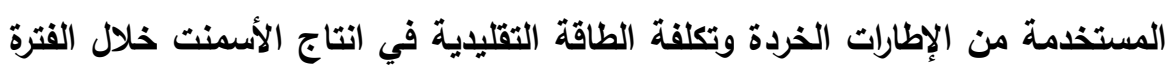

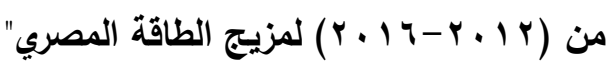

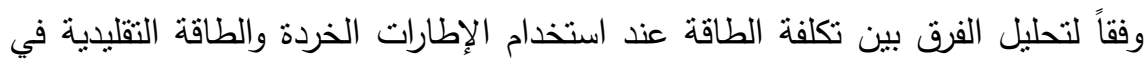

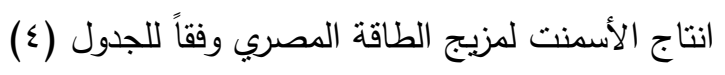


جدول(§): الفرق بين تكلفة الطاقة من استخدام الإطارات الخردة وتكلفة الطاقة التقليدية في

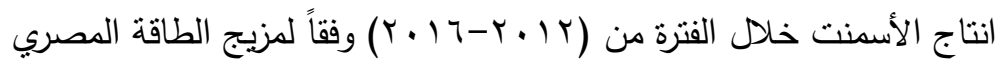

\begin{tabular}{|c|c|c|c|c|c|}
\hline \multirow[b]{2}{*}{ مستوى } & \multirow[b]{2}{*}{ قيمة ت } & \multicolumn{2}{|c|}{ تكلفة الطاقة } & \multirow[b]{2}{*}{ مجموعة المقارنة } & \multirow[b]{2}{*}{ نوع الوقود } \\
\hline & & الانحراف & المتوسط & & \\
\hline \multirow{2}{*}{$\cdot, \cdot 1 r$} & \multirow{2}{*}{$\varepsilon, \varepsilon \cdot 7$} & IVVY,T. & $\sum V \varepsilon \Sigma, \cdot r \wedge$ & قبل استخدام الإطارات الخردة & \multirow{2}{*}{ لغاز الطبيعي } \\
\hline & & 1111,91 & $r \leq \varepsilon r, .01$ & بعد استخدام الإطارات الخردة & \\
\hline \multirow{2}{*}{$\cdot, \cdot 1 r$} & \multirow{2}{*}{$\varepsilon, r V \cdot$} & rrтq,qV & $\wedge \varepsilon \cdot \wedge, \wedge \wedge \vee$ & قبل استخدام الإطارات الخردة & \multirow{2}{*}{ المازوت } \\
\hline & & $r \mid r \leqslant, r q$ & $7119, \leq \leqslant r$ & بعد استخدام الإطارات الخردة & \\
\hline \multirow{2}{*}{$\cdot,+1 \cdot$} & \multirow{2}{*}{$\varepsilon, O \wedge r$} & $\varepsilon q \mu 1, r q$ & $1 M 10 \mathrm{r}, 9 \mathrm{rV}$ & قبل استخدام الإطارات الخردة & \multirow{2}{*}{ الاجمالي } \\
\hline & & $r$ rT.,Ar & 9710,199 & بعد استخدام الإطارات الخردة & \\
\hline
\end{tabular}

المصدر: اعداد الباحث في ضوء تحليل بيانات الدراسة

يتضح من بيانات جدول (ع) وجود فروق ذات دلالة إحصائية بين نكلفة الطاقة

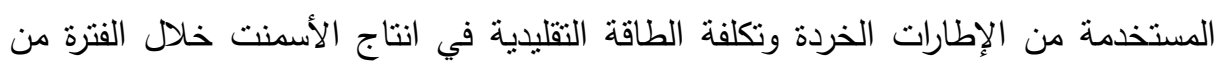

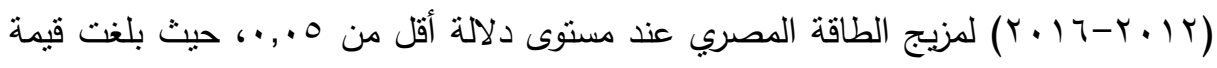

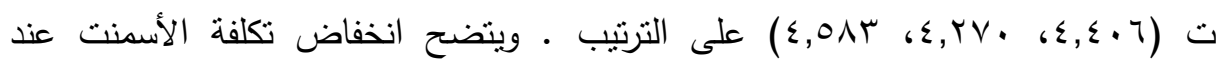
استخدام الإطارات الخردة. القرار: قبول صحة فرض الاراسة القائل "توجد فروق ذات دلالة إحصائية في تكلفة الطاقة المنوفرة من استخدام الإطارات الخردة وتكلفة الطاقة التقليدية في انتاج الأسمنت خلاد دات دالفته

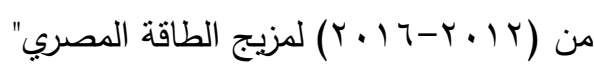
اختبار صحة الفرض الثالث: أبن

r- ينص الفرض الثالث على: " توجد فروق ذات دلالة إحصائية بين تكلفة الطاقة

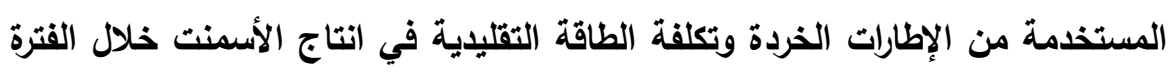

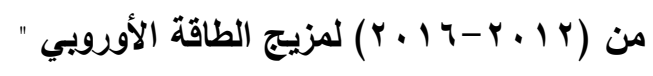

وفقاً لتحليل الفرق بين تكلفة الطاقة عند استخدام الإطارات الخردة والطاقة التقليدية في

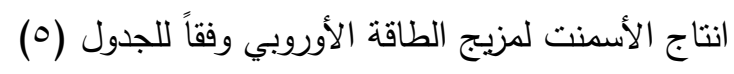


جدول(ه): الفرق بين تكلفة الطاقة من استخدام الإطارات الخردة وتكلفة الطاقة التقليدية في

\begin{tabular}{|c|c|c|c|c|c|}
\hline \multirow[b]{2}{*}{ مستوى الدلاذة } & \multirow[b]{2}{*}{ قيمة ت } & \multicolumn{2}{|c|}{ تكلفة الطاقة } & \multirow[b]{2}{*}{ مجموعة المقارنة } & \multirow[b]{2}{*}{ نوع الوقود } \\
\hline & & الانعرافي & المتوسط & & \\
\hline \multirow{2}{*}{$\cdot, \cdot, 1 Y$} & \multirow{2}{*}{$\varepsilon, \varepsilon, 0$} & $09,1 Y$ & $10 \Lambda, 1 \Gamma \varepsilon$ & قبل استخدام الإطارات الخردة & \multirow[b]{2}{*}{ الغاز الطبيعي } \\
\hline & & $r v, V r$ & $\prod \varepsilon, \vee \wedge$ & بعد استخدام الإطارات الخردة & \\
\hline \multirow{2}{*}{$\cdot, \cdot 1 r$} & \multirow{2}{*}{$\varepsilon, Y 70$} & OVY,rY & $1 \leqslant V \mid, \leqslant$. & قبل استخدام الإطارات الخردة & \multirow[b]{2}{*}{ المازوت } \\
\hline & & rvi,. & $1 \cdot V \cdot, 71$ & بعد استخدام الإطارات الخردة & \\
\hline \multirow{2}{*}{$\cdot, \ldots 7$} & \multirow{2}{*}{$0, Y 10$} & $1,11, \mathrm{~V} 1$ & ro9r,97 & قبل استخدام الإطارات الخردة & \multirow{2}{*}{ الفحم } \\
\hline & & $099, \Sigma 7$ & rqI r,. $q$ & بعد استخدام الإطارات الخردة & \\
\hline \multirow{2}{*}{$\cdot, \cdots \wedge$} & \multirow{2}{*}{$\varepsilon, 90}$. & $17 . r, V 9$ & OrTr,T4 & قبل استخدام الإطارات الخردة & \multirow{2}{*}{ الاجمالي } \\
\hline & & $9 \vee \wedge, \cdot \wedge$ & rVqV,Tr & بعد استخدام الإطارات الخردة & \\
\hline
\end{tabular}

المصدر : اعداد الباحث في ضوء تحليل بيانات الدراسة

يتضح من بيانات جدول (0) وجود فروق ذات دلالة إحصائية بين تكلفة الطاقة

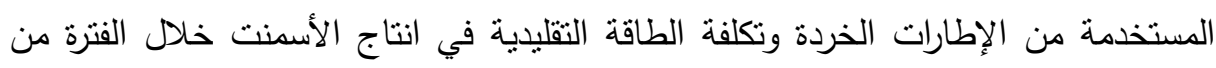

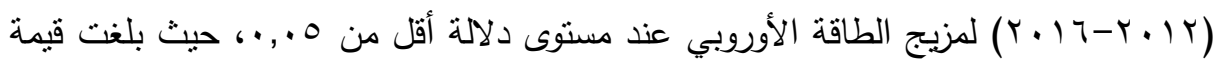

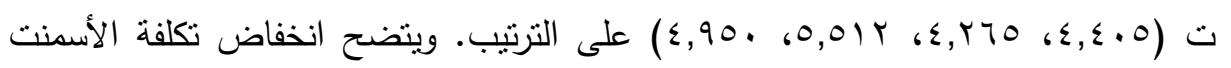
عند استخدام الإطارات الخردة.

القرار: قبول صحة فرض الاراسة القائل نوجد فروق ذات دلالة إحصائية بين تكلفة الطاقة

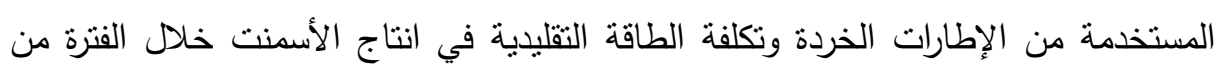

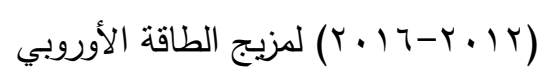

اختبار صحة الفرض الرابع:

ع - ينص الفرض الرابع على: " توجد فروق ذات دلالة إحصائية بين تكلقة الطاقة

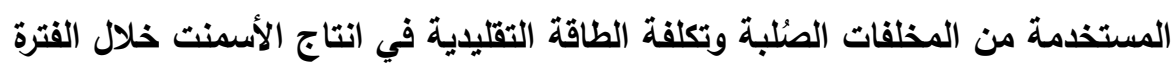

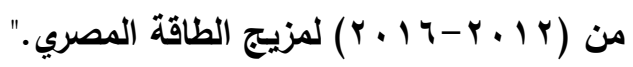

وفقاً لتحليل الفرق بين تكلفة الطاقة عند استخدام المخلفات الصُلبة والطاقة التقليدية في

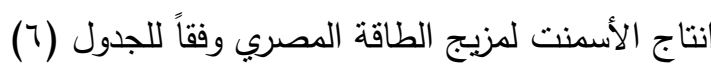


جدول(؟): الفرق بين تكلفة الطاقة من استخدام المخلفات الصُّلبة وتكلفة الطاقة التقليدية في

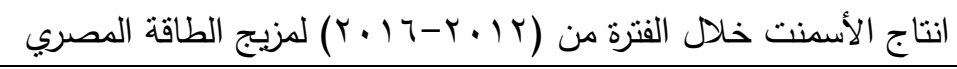

\begin{tabular}{|c|c|c|c|c|c|}
\hline \multirow[b]{2}{*}{ مستولة } & \multirow[b]{2}{*}{ 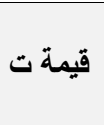 } & \multicolumn{2}{|c|}{ تكلفة الطاقة } & \multirow[b]{2}{*}{ مجموعة المقارنة } & \multirow[b]{2}{*}{ نوع الوقود } \\
\hline & & المعياري & المتوسط & & \\
\hline \multirow{2}{*}{$\cdot, \ldots$} & \multirow{2}{*}{0,797} & IVVY,T. & $\varepsilon V \varepsilon \varepsilon, \cdot \Gamma \wedge$ & قبل استخدام المخلفات الصُّلبة & \multirow{2}{*}{ الغاز الطبيعي } \\
\hline & & $T r \varepsilon, T V \varepsilon$ & $10 ., 0$ Yo & بعد استخدام المخلفات الصُلبة & \\
\hline \multirow{2}{*}{$\cdot, \cdots$} & \multirow{2}{*}{0,017} & rY११,QY & $\Lambda \varepsilon \cdot \wedge, \wedge \wedge \mathrm{V}$ & قبل استخدام المخلفات الصُّلبة & \multirow[b]{2}{*}{ 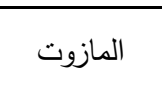 } \\
\hline & & $\varepsilon 0 \xi, \ldots \varepsilon$ & $r \cdot \varepsilon, 74 \Lambda$ & بعد استخدام المخلفات الصُلبة & \\
\hline \multirow{2}{*}{$\cdot, \ldots$} & \multirow{2}{*}{$0,7 \wedge 7$} & ह9Tा,ए & Tr10Y,9YV & قبل استخدام المخلفات الصُلبة & \multirow{2}{*}{ الاجمالي } \\
\hline & & TAY,YYV & $\varepsilon 00, Y \cdot r$ & بعد استخدام المخلفات الصُلبة & \\
\hline
\end{tabular}

المصدر: اعداد الباحث في ضوء تحليل بيانات الدراسة المبن

يتضح من بيانات جدول (T) وجود فروق ذات دلالة إحصائية بين تكلفة الطاقة

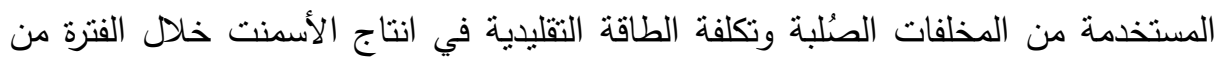

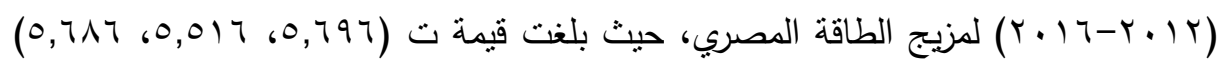
على الترتيب. ويتضح انخفاض تكلفة الأسمنت عند استخدام المخلفات الصُلبة. القرار: قبول صحة فرض الدراسة القائل "توجد فروق ذات دلالة إحصائية بين تكلفة الطاقة

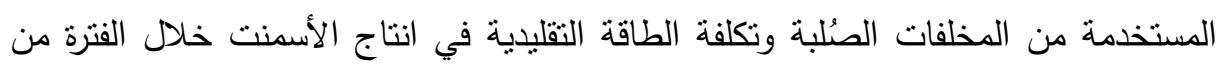

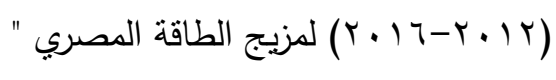
اختبار صحة الفرض الخامس: ه- ينص الفرض الخامس على: " توجد فروق ذات دلالة إحصائية بين تكلفة الطاقة

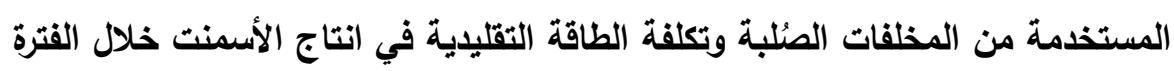

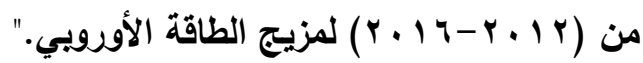
وفقاً لتحليل الفرق بين تكلفة الطاقة عند استخدام المخلفات الصُلبة والطاقة التقليدية في

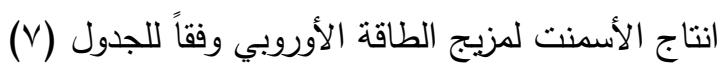


جدول(V): الفرق بين تكلفة الطاقة من استخدام الإطارات الخردة وتكلفة الطاقة التقليدية في

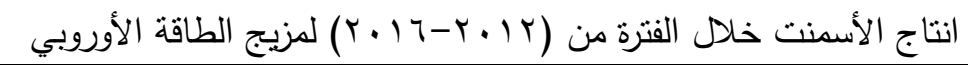

\begin{tabular}{|c|c|c|c|c|c|}
\hline \multirow[b]{2}{*}{ الدلالة } & \multirow[b]{2}{*}{ قيمة ت } & \multicolumn{2}{|c|}{ تكلفة الطاقة } & \multirow[b]{2}{*}{ مجموعة المقارنة } & \multirow[b]{2}{*}{ نوع الوقود } \\
\hline & & الالتحراف & المتوسط & & \\
\hline \multirow{2}{*}{$\cdot, \ldots$} & \multirow{2}{*}{$0,79 \leq$} & $09,1 Y$ & 10人,1Ts & قبل استخدام المخلفات الصُلبة & \multirow{2}{*}{ الغاز الطبيعي } \\
\hline & & $\vee, \wedge \cdot 1$ & $0, \cdot \leq Y$ & بعد استخدام المخلفات الصُّلبة & \\
\hline \multirow{2}{*}{$\cdot, \ldots$} & \multirow{2}{*}{0,010} & OVY,YT & $1 \leqslant V \mid, \varepsilon$. & قبل استخدام المخلفات الصُلبة & \multirow{2}{*}{ 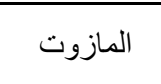 } \\
\hline & & Vq,AYO & or,rA. & بعد استخدام المخلفات الصُلبة & \\
\hline \multirow{2}{*}{$\cdot, \cdots r$} & \multirow{2}{*}{$V, r M q$} & $1 \cdot 11, \times 1$ & ro9r,97 & قبل استخدام المخلفات الصُلبة & \multirow{2}{*}{ الفحم } \\
\hline & & $1 \wedge 7, \cdot 11$ & $111, .07$ & بعد استخدام المخلفات الصُلبة & \\
\hline \multirow{2}{*}{$\cdot, \cdot r$} & \multirow{2}{*}{\urcorner$, \vee \wedge)$} & $17 . r, 199$ & OYYT,TT & قبل استخدام المخلفات الصُلبة & \multirow{2}{*}{ الاجمالي } \\
\hline & & TVT,.97 & WI,TO & بعد استخدام المخلفات الصُلبة & \\
\hline
\end{tabular}

المصدر : اعداد الباحث في ضوء تحليل بيانات الدراسة

يتضح من بيانات الجدول (0) وجود فروق ذات دلالة إحصائية بين تكلفة الطاقة

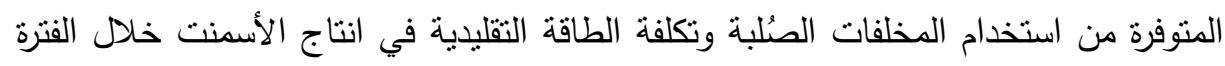

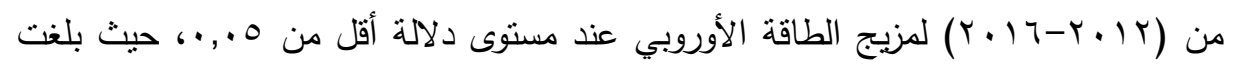

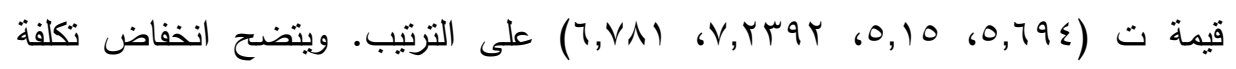
الأسمنت عند استخدام المخلفات الصُّلبة.

القرار: قبول صحة فرض الاراسة: "توجد فروق ذات دلالة إحصائية بين تكلفة الطاقة

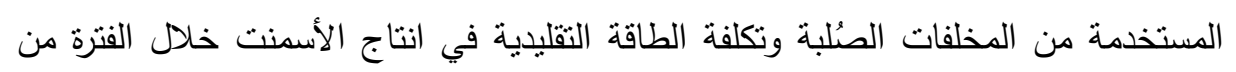

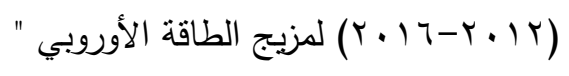

\section{التهوصياهي}

من واقع النتائج السابقة ولتحقيق أهداف الدراسة يستعرض الباحث مجموعة من

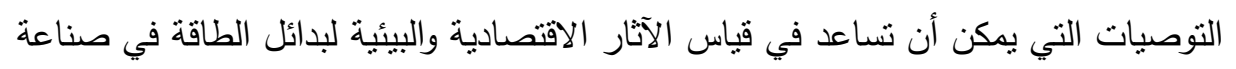

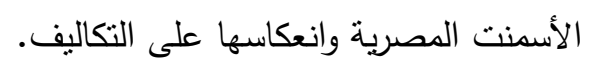
1- يوصى الباحثون بوضع إطار نظامي لتجميع الإطارات الخردة في مخازن مركزية بالثركات العاملة في مجال النقل وتقديم خدمات اصلاح واستبدال الإطارات. 
r- انشاء نظام مالي لمستهكي الإطارات لتجميع كهنة الإطارات كخفض نسبة من الثن عند

$$
\text { الاستبدال وشراء الجديد وترك القديم منها. }
$$

r- انشاء مصانع لإعادة تدوير المخلفات الصلبة التي يتم تجميعها للاستفادة منها كوقود في

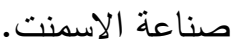

ع - تحديث خطوط انتاج مصانع الاسمنت في مصر لتعمل بالطريقة الجافة. 0- تحديد المصانع التي سوف تستخدم الوقود البديل وتطوير خطوط انتاجها لتعمل بالوقود البديل.

\section{مرايج السراسة}

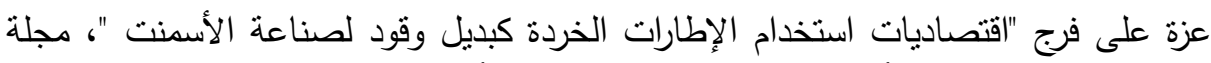

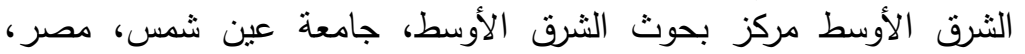

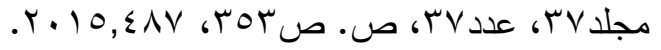

موقع المنظمة العربية للتتمية الصناعية والتعدين، مشروع مواصفات قياسية عربية(بتاريخ

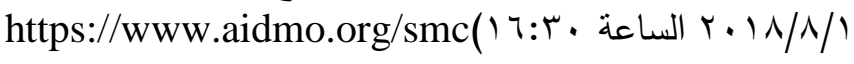

نعيمة حسن رمضان سليمان "قياس بعض الآثار البيئية غير المباشرة لصناعة الأسمنت في الإني

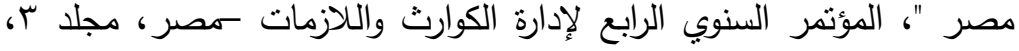

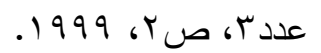

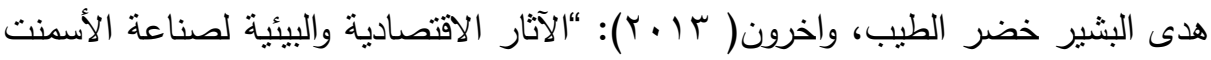

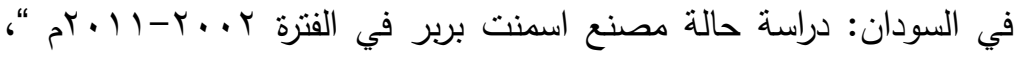

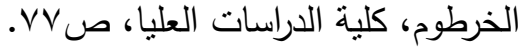

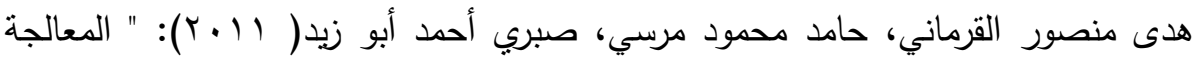

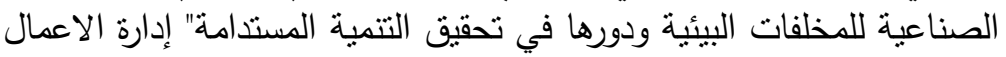

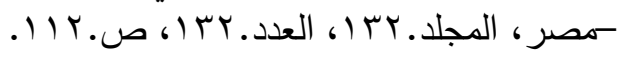

هيئة التحرير (عارض)، "الملتقي العلمي السنوي الثالث لقطاع الأسمنت بعنوان مستقبل

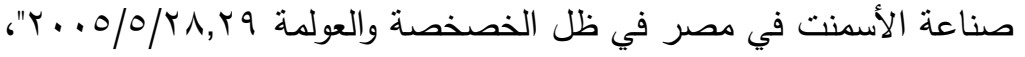

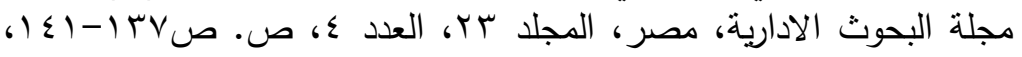

$$
. \text {. . . O }
$$


Demirel، Yaşar. (2012): "Energy and energy types." In Energy book، Springer, London' p. 28.

Dina Czajczy-nska a, b, Renata Krzy-zy-nska a., *، Hussam Jouhara b, Nik Spencer c., (2017): " Use of pyrolytic gas from waste tire as a fuel: A review"، Energy، vol 134. Issue 134، p.1121.

J. H. Sharp,(2006): " Surely we know all about cement - don't we?" Advances in Applied Ceramics، vol105، issue4، p.166.

Oschman، James L( 2015): "Energy Medicine-E-Book: The Scientific Basis." Elsevier Health Sciences‘ p.1.

Stajanča M، Eštokova A(2012):” Environmental Impacts Of Cement Production" Civil Engineering Faculty، Institute of Architectural Engineering، p.296.

Bosoaga, A., Masek, O, and Oakey, J.E (2009): " $\mathrm{CO}_{2}$ capture technologies for cement industry", Energy Procedia, Vol. 1, issue. 1 , pp. 134,.

Morrow III, William R., Ali Hasanbeigi, Jayant Sathaye, and Tengfang $\mathrm{Xu}$. "Assessment of energy efficiency improvement and $\mathrm{CO}_{2}$ emission reduction potentials in India's cement and iron \& steel industries." Journal of Cleaner Production65, pp.131-141, 2014. 
مجلة العلوم البيئية

معهد الدراسات والبحوث البيئية - جامعة عين شمس لينان

\title{
THE ECONOMIC AND ENVIRONMENTAL IMPLICATIONS OF ENERGY'S ALTERNATIVES IN THE EGYPTIAN'S CEMENT INDUSTRY AND ITS REFLECTION ON THE COSTS
}

\author{
Ahmed N. S. Mohamed (1); Amr H. Abd El Bar (1); \\ Eid R. Abd El Kader ${ }^{(1)}$ and Huda I. A. Helal (2) \\ 1) Faculty of Commerce, Ain Shams University 2) Institute of \\ Environmental Studies \& Research, Ain Shams University
}

\begin{abstract}
This study presents the economic and environmental importance of the use of energy alternatives in the provision of energy for the production of cement in Egypt. In light of this ' the cement industry is considered to be one of the energy intensive industries. It also shows the economic effects of using these alternatives in providing thermal energy for the production of cement. The cost of purchasing and supporting fossil fuels (conventional energy used in the cement industry)، which amounts to millions of dollars and the amount of savings in total energy costs when using these alternatives (scrap tires and waste).

The objectives of the study are to identify alternatives to energy that can be used in the cement industry, to determine the economic and environmental impacts of the energy alternatives used in the cement industry, the possibility of using scrap tires and solid waste as an alternative to fossil fuels in reducing the cost of the cement industry, In order to achieve the objectives of the study, in the study and deductive to confirm the validity of the hypotheses of the study, The study has reached the following results: Cement contributes to solving the problem of unemployment, causing the cement industry and other heavy industries to cause environmental pollution and to reflect harmful
\end{abstract}

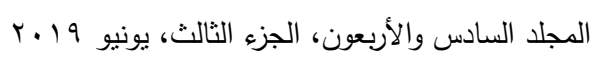


effects on man, water, air and soil. The entry into the field of waste recycling leads to the reduction of environmental degradation and depletion of resources. This preserve them for future generations, thus achieving the principle of sustainable development, The most important recommendations of the researchers are: - Attention to the economic dimensions of solid waste and scrap tires for the gains that help in opening up areas for export through the development of standards for the operation and utilization of waste dumps. The establishment of a unit responsible for waste management in the environmental protection institution to provide the necessary funding and training to follow up Waste management and scrap tires, implementing legislation that includes the proper management of waste through collection, transport and recycling), attention to the use of modern methods of waste management and scrap tires will have positive impacts on the health of individuals within the district Because the rapid disposal and nonaccumulation for a period so as not to decompose and be a cause of environmental pollution and thus the transfer of many diseases.

The study reached the following results: Key Words (Cement industry - Scrap tires - Waste transfer to energy - Environmental effects of the cement industry) 